\title{
Propiedades militares y nuevas áreas de centralidad. El caso de la Plaza de Armas de Milán
}

\author{
Federico Camerin ${ }^{1}$ \\ Recibido: 10-02-2021 | en su versión final: 26-03-2021
}

Resumen

\begin{abstract}
El objetivo de este trabajo es relatar el proceso de construcción de la ciudad de Milán a partir de la materialización-abandono-regeneración de sus Plazas de Armas desde el siglo XIX hasta la actualidad. En el caso milanés se demuestra que tales procesos, a lo largo del tiempo, están íntimamente relacionados con las dinámicas urbanas y territoriales que, a través de los instrumentos urbanísticos, contribuyen a crear una ciudad segregada de alcance metropolitano a través de grandes proyectos urbanos. El proceso de construcción de la ciudad, a partir de la materialización de las primitivas Plazas de Armas, de sus sucesivos desplazamientos hacia otros lugares, incluso, o su desaparición en el panorama urbano y territorial, es un tema poco estudiado en las ciudades europeas occidentales. En el caso italiano, concretamente en Milán, nos encontramos con el siguiente fenómeno. El cambio de localización de su original Plaza de Armas, a partir de los primeros años del siglo XIX, ha tenido lugar hasta tres veces, proceso que ha acabado con la definitiva desaparición de las actividades militares en el marco de este particular tipo de asentamiento militar, lo que sucedió a finales de los años 80 del siglo pasado. El artículo, en fin, demuestra cómo la gestión de tales grandes propiedades de suelo subyace a unas estrategias, programas urbanísticos proyectuales y de planificación e implementación muy similares entre ellos, no obstante, se desarrollen en distintas fases del proceso de desarrollo urbano.
\end{abstract}

Palabras clave: Ciudad capitalista; desarrollo urbano; renovación urbana; regeneración urbana

\section{Military Properties and New Areas of Centrality. The Case of the Parade Ground in Milan}

\begin{abstract}
This paper aims at analysing the city-making process of Milan on the ground of the building abandonment-regeneration of the Parade Ground from the 19th century onwards. The case of Milan shown that such processes are intimately related to urban and territorial dynamics over time, which impacts, through urban planning instruments, is the creation of a segregated city with a large urban projects-based metropolitan scope. Few studies were carried out on the western European city-making process based on the construction of the primitive Parade Ground, of its successive displacements to other places until its disappearance in the urban and territorial panorama. In the Italian case, specifically in Milan, a specific phenomenon took place. The original Parade Ground dated back to the early 19th century and its change of location has taken place up to three times, which ended in the late 1980s with the definitive disappearance of military activities within the framework of this particular type settlement. To sum up, this work shows how the management of such large land properties is based on strategies, urban planning and implementation programmes very similar to each other, although that they are developed in different phases of the urban development process.
\end{abstract}

Keywords: Capitalist city; urban development; urban renewal; urban regeneration

1 Dr. Becario de investigación post-doctoral en Urbanismo (assegnista di ricerca in urbanistica), Università IUAV di Venezia - Dipartimento di Culture del Progetto (ORCiD: 0000-0002-8659-3761, Scopus Author ID: 57193016490, ResearcherID: AAX-5847-2020). Correo de contacto: fcamerin@iuav.it 


\section{Introducción. La Plaza de Armas: de espacios institucional-castrenses a 'nuevas centralidades'}

El artículo analiza los procesos de materialización, abandono y regeneración de la antigua Plaza de Armas de la ciudad italiana de Milán a través de la interpretación de fuentes primarias y secundarias obtenidas a partir de una revisión sistemática de la literatura sobre el tema y, en el caso específico de la Plaza de Armas de Milán, la consulta de los manuscritos originales y la documentación gráfica disponible en los archivos del Ayuntamiento de Milán y en línea', las visitas de campo a la zona en septiembre de 2015 y noviembre de 2017, y las entrevistas con académicos expertos ${ }^{2}$ del Politécnico de Milán (Italia).

El interés de estudiar el caso específico de las "Plazas de Armas" de Milán y las transformaciones urbanas a éstas conectadas durante dos siglos surge en cuanto el fenómeno de la enajenación del patrimonio inmobiliario militar desde el siglo XIX hasta la actualidad ha sido un tema de creciente interés en los estudios urbanos en Italia (Storelli y Turri, 2014; Santarossa y Scirè Risichella, 2016; Fiorino, 2017; Gastaldi y Camerin, 2019) y en ámbito internacional (Bagaeen y Clark, 2016; Sánchez Pingarrón, 2018). Sin embargo, los análisis sobre las transformaciones urbanas en conexión con los procesos de enajenación de las propiedades militares han dejado en segundo plano el hilo conductor que conecta lo acaecido entre el siglo XIX y la primera mitad del siglo XX (Aa. VV., 1989; Savorra y Zucconi, 2009; Mas Hernández, 2003; Devoti, 2018) con los programas de enajenación de los terrenos militares y su reconversión a partir de finales del siglo XX hasta la actualidad (Camerin, 2020; Addison y Artioli, 2020). Con la finalidad de colmar esta brecha de investigación, se ha emprendido un recorrido que ha llevado a descubrir el fuerte vínculo entre las dinámicas urbanas, los instrumentos de planificación urbana y la presencia militar en la ciudad a través de un caso ejemplar, el de Milán. La hipótesis de base de este estudio es la siguiente. En los procesos de transformación urbana desde el siglo XIX hasta la actualidad que han afectado Milán, así como a otras ciudades italianas y también europeas, muchas de las operaciones que han marcado el cambio en la ciudad se han gestionado siguiendo las pautas del proceso de desagregación socio-espacial que transformó, paulatinamente y de forma radical, la ciudad heredada (Álvarez Mora, 1996). En particular se focaliza la atención en los procesos de renovación-regeneración urbana de una específica tipología de suelo público, aquella donde alberga la actividad militar, y como su gestión a lo largo del tiempo resultó en la materialización de funciones puestas al servicio de intereses particulares, así como sucedió con propiedades de suelo procedentes de diferentes usos, ferrocarril, mercados, colegios, industrias, entre otras (Solà-Morales i Rubió et al., 1974; Álvarez Mora, 1979, Aguilar et al., 1980; Apur, 1987) siguiendo las pautas de los modelos de desarrollo urbano correspondientes. En general, la reutilización de las áreas públicas ha planteado nuevas demandas y contribuido decisivamente a la innovación disciplinar en los campos de la arquitectura, el urbanismo y la planificación urbana (Oliva, 1993: 96-98; Gaeta y Savoldi, 2013). En principio la necesidad de repensar la forma y las funciones de partes enteras de la ciudad ha influenciado la manera de hacer ciudad desde el siglo XIX en adelante (Zucconi, 1989). Primero, a través de la gestión de grandes propiedades de suelo público, la construcción de la ciudad ha apostado por el crecimiento de la ciudad existente del siglo XIX hasta promover la dimensión del proyecto urbano de finales del siglo XX (Macchi Cassia, 1999), todo eso apoyándose a la promoción inmobiliaria que ha ido creando siempre más áreas de nueva centralidad y nuevas zonas marginales (Mas Hernández, 1999). Segundo, las variaciones requeridas para satisfacer las solicitudes de transformación del entorno urbano han erosionado la credibilidad del plan tradicional y han desplazado la atención hacia modelos que responden a las exigencias del gran proyecto urbano (De Ureña, 2020). Finalmente, y como consecuencia, la necesidad de coordinar y llevar a cabo las

\footnotetext{
${ }^{1}$ Como los Archivi Storici del Politecnico di Milano (http://www.archivinmostra.polimi.it/it/67/archivi-storici-politecnicodi-milano).

2 Se agradece al profesor Federico Oliva (1945-2018) por la entrevista con el autor de este artículo en junio de 2017. Además, un agradecimiento particular al profesor Alfonso Álvarez Mora por su apoyo en el planteamiento del análisis sobre el proceso de construcción de la ciudad capitalista.
}

ACE, 16 (4.6) CC BY-ND 3.0 ES | UPC Barcelona, España | Propiedades militares y nuevas áreas de centralidad. El 2 caso de la Plaza de Armas de Milán. DOI: http://dx.doi.org/10.5821/ace.16.46.10366 


\section{ACE Architecture, City and Environment}

intervenciones en grandes cantidades de suelo ha estimulado nuevas demandas que responden a una lógica basada en una nueva imagen de ciudad, que ha ido levantando los nuevos iconos que expresan el contenido competitivo con el que se quiere dotar a la ciudad (Muñoz, 2008).

En el caso milanés se observa un hilo conductor que relaciona el recorrido del discurso que dotó de toda lógica a las transformaciones urbanas vinculadas con la gestión de la Plaza de Armas (Tabla 1 y Figuras 1 y 2 en que aparecen indicados los diferentes emplazamientos). Se trata de un hilo conductor que responde a la puesta en marcha de concretas operaciones de centralidad.

Tabla 1. Resumen del recorrido construcción-abandono-regeneración de las Plazas de Armas de Milán

\begin{tabular}{|c|c|c|c|c|}
\hline Período & Localización & $\begin{array}{c}\text { Forma de } \\
\text { apropiación del } \\
\text { espacio urbano }\end{array}$ & $\begin{array}{c}\text { Herramientas de } \\
\text { planificación urbana }\end{array}$ & Usos \\
\hline 1806-1809 & $\begin{array}{l}\text { Bordes del centro } \\
\text { histórico urbano }\end{array}$ & $\begin{array}{c}\text { Demolición de } \\
\text { murallas }\end{array}$ & $\begin{array}{c}\text { Ninguna (orden de } \\
\text { Napoleón) }\end{array}$ & $\begin{array}{c}\text { Primera Plaza de } \\
\text { Armas }\end{array}$ \\
\hline 1861-1889 & $\begin{array}{c}\text { Terrenos periféricos } \\
\text { no edificados }\end{array}$ & $\begin{array}{c}\text { Intercambio y } \\
\text { compra de terrenos }\end{array}$ & $\begin{array}{c}\text { Plan Regulador (1994- } \\
1889)\end{array}$ & $\begin{array}{c}\text { Segunda Plaza de } \\
\text { Armas }\end{array}$ \\
\hline $1906-1923$ & $\begin{array}{l}\text { Terrenos rurales no } \\
\text { edificados }\end{array}$ & $\begin{array}{l}\text { Intercambio y } \\
\text { compra de terrenos }\end{array}$ & $\begin{array}{l}\text { Plan Regulador de } \\
\text { Masera-Pavia (1909- } \\
\text { 1912) }\end{array}$ & $\begin{array}{c}\text { Tercera Plaza de } \\
\text { Armas }\end{array}$ \\
\hline $1926-1934$ & $\begin{array}{c}\text { Entorno a la tercera } \\
\text { Plaza de Armas }\end{array}$ & $\begin{array}{c}\text { Construcción de } \\
\text { nuevos } \\
\text { asentamientos } \\
\text { militares durante el } \\
\text { fascismo }\end{array}$ & $\begin{array}{c}\text { 1926-1927: Competición } \\
\text { para el nuevo Plan } \\
\text { Regulador }\end{array}$ & Ciudad Militar \\
\hline 2005-actualidad & $\begin{array}{c}\text { Plaza de Armas- } \\
\text { Almacenes de } \\
\text { Baggio }\end{array}$ & $\begin{array}{l}\text { Abandono y } \\
\text { creación nueva }\end{array}$ & PGT 2012 y 2019 & $\begin{array}{l}\text { Área de nueva } \\
\text { centralidad }\end{array}$ \\
\hline
\end{tabular}

Fuente: Elaboración propia (2021)

Figura 1. Evolución histórica de la ubicación de las tres plazas de armas en Milán

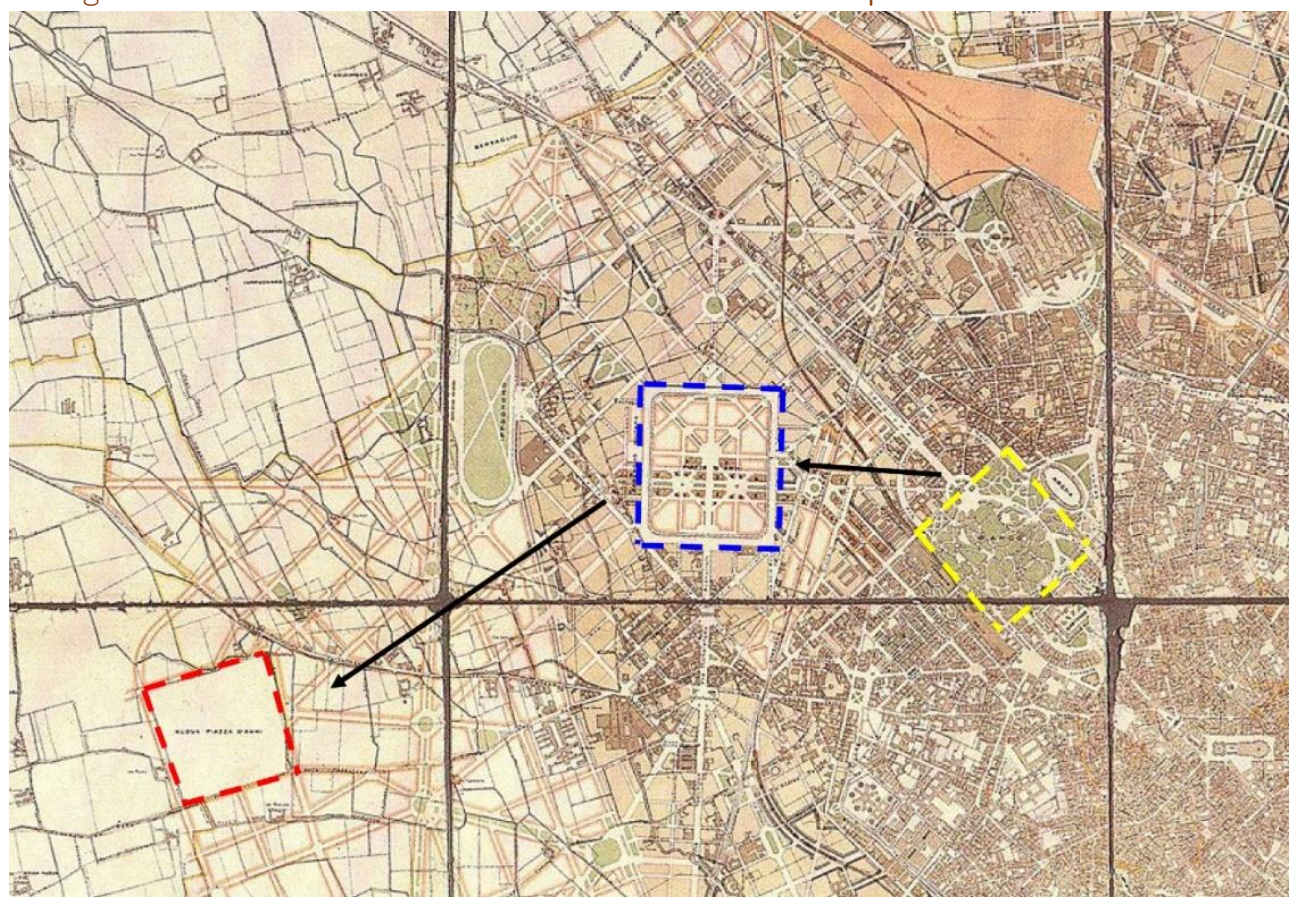

Fuente: Elaboración propia a partir del mapa incluido en Ugolini (2016: 136). Cartografía: mapa del Istituto Geografico Militare de 1888, a la que se han superpuesto los Planes de Beruto (1889) y de Pavia-Masera (1912).

ACE, 16 (4.6) CC BY-ND 3.0 ES | UPC Barcelona, España | Propiedades militares y nuevas áreas de centralidad. El caso de la Plaza de Armas de Milán. DOI: http://dx.doi.org/10.5821/ace.16.46.10366 


\section{ACE Architecture, City and Environment}

E-ISSN 1886-4805

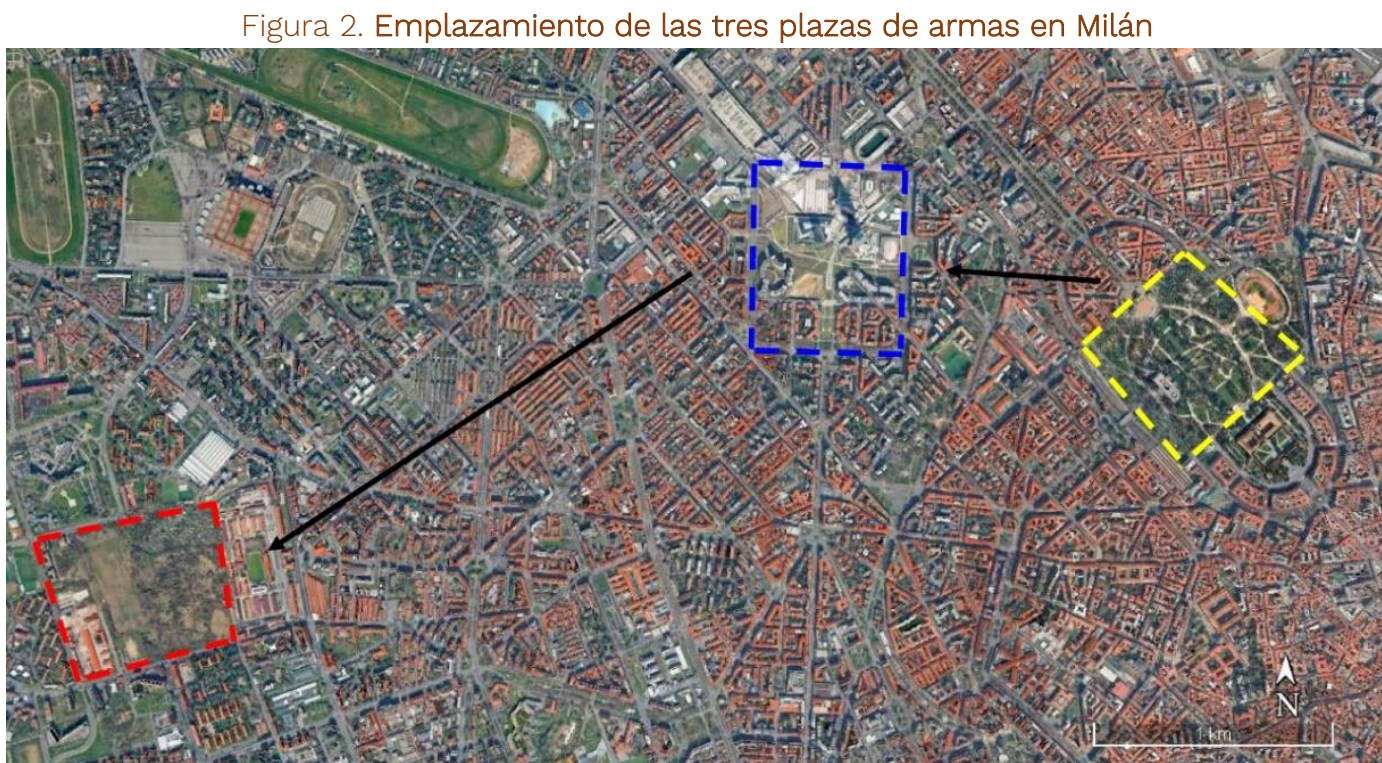

Fuente: Elaboración propia a partir de ortofotografía de 2021 que ilustra la ubicación de las tres plazas de armas en Milán. Se indican las tres plazas de armas como en la Figura 1.

El proceso de materialización de la Plaza de Armas, en efecto, remite a tres momentos históricos diferentes, que recorren el espacio de tiempo comprendido entre 1800 y los años 20 del siglo pasado, correspondiéndose, cada uno de ellos, con la evolución, en sus pautas de desarrollo, del modelo urbano desagregado. Proceso que procuró toda una serie de equipamientos y servicios urbanos vinculados, eso sí, a demandas específicas derivadas del proceso de producción capitalista.

En una primera fase, que se corresponde con los comienzos del siglo XIX (1809), la Plaza de Armas se materializa sobre los restos de las antiguas murallas de la ciudad, construyéndose por orden de Napoleón Bonaparte, en tiempos de la dominación francesa. El propósito de dicha Plaza de Armas era establecer un "centro institucional", a manera de "espacio cívico", que expresase el sentir de la "ciudad republicana”. Estamos hablando del llamado Foro Bonaparte, adyacente al Castillo Sforzesco, el cual fue convertido, a su vez, en un cuartel.

En un segundo momento (1889), asistimos a un primer desplazamiento de dicha Plaza de Armas con la finalidad de reconvertir dicho espacio en una "área de centralidad" con características civiles. Esto dio lugar al Parque Sempione, ocupando el suelo dejado por el Foro Bonaparte, al que se le unió el Castillo para que albergase funciones institucionales y culturales. Todo ello, a cambio del aprovechamiento de determinados terrenos para edificar, así como del desplazamiento de los militares, quienes pasarían a colonizar los ámbitos de la primera periferia milanesa.

En un tercer momento (1923), y aprovechándose de la paulatina dotación de servicios urbanos de que había sido objeto el lugar de la Plaza de Armas, lo que contribuyó a crear las condiciones idóneas para desarrollar el fenómeno de la "centralidad urbana", se pensó en localizar, en dicho lugar, la Feria de Muestras, lo que obligó a un nuevo desplazamiento de los militares que aún hacían uso de dicho ámbito, hacia la periferia urbana, pensándose, en esta ocasión, hacia 1920, en la creación de una "Ciudad Militar", fuera del contexto urbanizado milanés, en la zona de Baggio. Esta nueva "periferia militar”, después de ser utilizada durante más de 50 años, se convirtió en un lugar rodeado, como puede imaginarse, por toda una serie de nuevos equipamientos urbanos, aunque caracterizada por una importante "fragilidad social", dada la presencia de migrantes y, en general, de grupos sociales con escasos recursos económicos, lo que determinó que se pensasen otras alternativas al lugar

ACE, 16 (46) CC BY-ND 3.0 ES | UPC Barcelona, España | Propiedades militares y nuevas áreas de centralidad. El caso de la Plaza de Armas de Milán. DOI: http://dx.doi.org/10.5821/ace.16.46.10366 
desde su condición de ámbito sujeto a operaciones especulativas. Instrumentando la planificación urbana, es cómo se ha procedido, con posterioridad, a la transformación de esta "área militar periférica", para dotarla de funciones que respondiesen a la creación de "nuevas centralidades", en esta ocasión, de alcance metropolitano, siguiendo las pautas del "modelo urbano disperso" (Álvarez Mora, 2004). Junto a estas otras "centralidades periféricas" se van consolidando aquellas otras que responden a la necesidad de crear "espacios de renta" (Álvarez Mora, 2015: 11-13) en la ciudad construida central. Este es el caso que nos ocupa, la casuística concreta de la antigua Plaza de Armas, más tarde Foro Napoleónico-Parque Sempione, en la ciudad de Milán.

\section{La construcción-desplazamiento-reconversión de la antigua Plaza de Armas}

Una vez introducido el recorrido que ha marcado la presencia de la Plaza de Armas en Milán, se analiza a continuación, con mayor detalle, las diferentes fases que han caracterizado la historia de estos cambios de desplazamiento, haciendo hincapié en los procesos de "abandono-vaciamientoregeneración” que han afectado, sobre todo, a las instalaciones militares allí asentadas.

Tras la demolición de las murallas que, en forma de estrella, defendían el Castillo Sforzesco, demolición ordenada por Napoleón, lo que tuvo lugar en 1800, se creó una Plaza de Armas contigua al mismo castillo, entre 1806 y 1809, convirtiéndose, este último, en un cuartel militar. Esta demolición respondía a la necesidad, exigida por Napoleón, de dotar al centro de la ciudad de un nuevo equipamiento institucional republicano, el llamado, por entonces, Foro Bonaparte (Scotti, 1989; D’Amia, 2021: 157-183). Esta nueva centralidad correspondía a un centro direccional en contraposición con aquello religioso correspondiente a la plaza del Duomo: sin embargo, este proyecto no verá la luz debido a la falta de recursos públicos y privados (Torricelli y Rampi, 1990: 872-874). Es importante subrayar que esta operación fue desarrollada en el período de dominación francesa en Italia, que cambió la relación entre los militares y la sociedad civil, asignándoles a los soldados algunas funciones que beneficiasen a los ciudadanos, como la asistencia sanitaria, la producción de pan, la seguridad, etcétera. De ahí que su ubicación ocupase un lugar de privilegio en la ciudad, es decir, su centro urbano (Della Peruta, 1988). De hecho, se dotó a la Plaza de Armas de un paseo público que permitiese el desarrollo tanto de actividades militares como de aquellas otras implicadas con la sociedad civil burguesa, es decir, compaginando lo castrense con actividades relacionadas con el uso del tiempo libre, con el ocio. La Plaza de Armas se comportaba, en suma, como una gran propiedad de suelo, dentro de la Ciudad Histórica, que desempeñaba un doble papel en el centro de Milán: ser utilizada por parte de los militares, y también por la ciudadanía (Antolini, 1814).

La permanencia de la Plaza de Armas y del cuartel en el Castillo Sforzesco en esta localización céntrica, comenzó a ponerse en entredicho tras la unificación del estado italiano (Torricelli y Rampi, 1990: 875-877), es decir, cuando las pautas del desarrollo urbano comenzaron a condicionar específicas acciones de reforma aplicadas al Centro Histórico, con el objetivo de fortalecer su papel de "lugar central", lo que imponía la expulsión, sobre todo, de funciones residenciales populares, así como de aquellas otras que no se adecuasen a los objetivos del capital, en su vertiente inmobiliaria, caso de las áreas militares.

A mediados del siglo XIX, la reforma del espacio urbano tradicional se correspondía con un crecimiento periférico, es decir, con el desarrollo de complejos residenciales populares, industrias, ferrocarril, etc., tal y como sucedía en otras grandes ciudades europeas, caso de Barcelona (Cerdà, 1867), Madrid (Bonet Correa, 1978) y París (Gaillard, 1977). Todas estas dinámicas se manifestaron en Milán impulsadas, sobre todo, por una sociedad inmobiliaria local, la llamada Società Fondiaria Milanese, la cual adquirió, a bajo coste, algunos terrenos para edificar en el sector noroeste de la

ACE, 16 (4.6) CC BY-ND 3.0 ES | UPC Barcelona, España | Propiedades militares y nuevas áreas de centralidad. El caso de la Plaza de Armas de Milán. DOI: http://dx.doi.org/10.5821/ace.16.46.10366 
Plaza de Armas, desplazando a los militares y asumiendo una parte del coste de la operación a través de los beneficios económicos derivados de la reconversión de la Plaza de Armas en suelo residencial. Todo ello, con el beneplácito del Ayuntamiento, ya que se trataba de un área de "dominio público", así como en consonancia con un desarrollo urbano determinado condicionado, entre otros, por el trazado del ferrocarril que se estaba construyendo, lo que contribuía a crear un "efecto urbanizador" en la capital milanesa. Una de las Estaciones de Ferrocarril construidas se emplazó en una de las nuevas zonas a urbanizar.

Este desplazamiento de la Plaza de Armas estaba estrictamente vinculado con la idea que subyacía al proyecto de ciudad en el que estaba empeñado la burguesía milanesa, es decir, en su materialización como "capital moral", "centro comercial y financiero", del Estado italiano (Rosa, 1982). Sin embargo, el Plan regulador edilicio y de ensanchamiento de la ciudad de Milán - Piano regolatore edilizio e di ampliamente della città di Milano en lengua italiana- proyectado por Beruto entre 1884 y 1889 (Boriani, Rossari y Rozzi, 1992), preveía, para la gran propiedad de suelo en la que se inscribía la Plaza de Armas, un gran parque urbano para uso del tiempo libre y para manifestaciones públicas. Estamos hablando del llamado parque Sempione.

También, estaba previsto, en dicho Plan, el uso del castillo Sforzesco para actividades ciudadanas, civiles, sedes institucionales, culturales, etc. Al final, con la aprobación del Plan, en 1889, la primitiva Plaza de Armas se desplazó al noroeste del parque, precisamente en terrenos ya adquiridos con anterioridad por la Società Fondiaria Milanese, la cual en 1887 cedió una porción del área, unos 116.500 $\mathrm{m}^{2}$, para la realización del "Distrito de las Milicias", al norte de los barrios burgueses, muy cerca de la explanada de maniobras "Sempione", con el objetivo de construir unos cuarteles ${ }^{3}$ en terrenos de bajo coste. Otro hecho histórico, por tanto, que condicionó el futuro destino de la nueva Plaza de Armas, hecho que no aparece desvinculado de la voluntad por recrear esa "centralidad" que exigía la burguesía local como condición sine qua non para posicionar a Milán como capital económica del Estado italiano (Cesa Bianchi, 1884; Allocchio, 1899).

Con ocasión de la Exposición Universal de 1906, por su parte, y debido a la cercanía de la nueva Plaza de Armas con respecto al parque Sempione, el área militar fue equipada con un nuevo sistema de alcantarillado, de verde público y de transporte (como el tranvía), para poder acoger algunas de las actividades de la Exposición (Figura 3), como fue el caso, por ejemplo, del pabellón de la "Galería del trabajo industrial", que tenía su sede central en dicho parque (Botti y Ricci, 2011).

Una vez que la Plaza de Armas fue dotada de servicios públicos, aprovechando el evento de 1906, la burguesía milanesa, la que estaba comprometida con la producción inmobiliaria, comenzó especular a propósito del futuro de dicha área, con el objetivo de plantear una nueva utilización que fuese lo más rentable posible. De hecho, después de haberse realizado las obras para la mejora de dicha Plaza, fortaleciendo su uso público, el Plan Regulador de Masera-Pavia, el llamado Piano generale regolatore edilizio e di ampliamento, redactado entre 1909 y $1912^{4}$, contemplaba un nuevo desplazamiento atendiendo al nuevo sistema de acuartelamiento de la ciudad, apoyado en la descentralización del ferrocarril, cuyo efecto urbanizador es, como se sabe, contundente.

Este nuevo planteamiento, cuyo enfoque es verdaderamente similar a lo que había sucedido a finales de la década de 1880, estaba en consonancia con específicos intereses del capital, el cual no dejaba de estar atento al desplazamiento de otras actividades "inadecuadas" localizadas en el espacio urbano tradicional, como es el caso de antiguos hospitales, industrias, sedes universitarias,

\footnotetext{
${ }^{3}$ Fueron los cuarteles Montebello y el Distrito Militar, que hoy en día están en uso, y el cuartel Majnoni, derribado durante los bombardeos de la segunda guerra mundial y substituido por una urbanización residencial a alta densidad.

${ }^{4}$ Su documentación se encuentra en https://www.rapu.it/ricerca/scheda piano.php?id piano=468
}

ACE, 16 (4.6) CC BY-ND 3.0 ES | UPC Barcelona, España | Propiedades militares y nuevas áreas de centralidad. El caso de la Plaza de Armas de Milán. DOI: http://dx.doi.org/10.5821/ace.16.46.10366 


\section{ACE Architecture, City and Environment}

determinadas instalaciones deportivas, etc. El objetivo era consolidar estos lugares como espacios terciarios y representativos, como espacios sociales de renta propios de la sociedad milanesa tardodieciochesca y de principios de siglo XX.

Figura 3. Planimetría de los pabellones de la Expo 1906 instalados en la Plaza de Armas

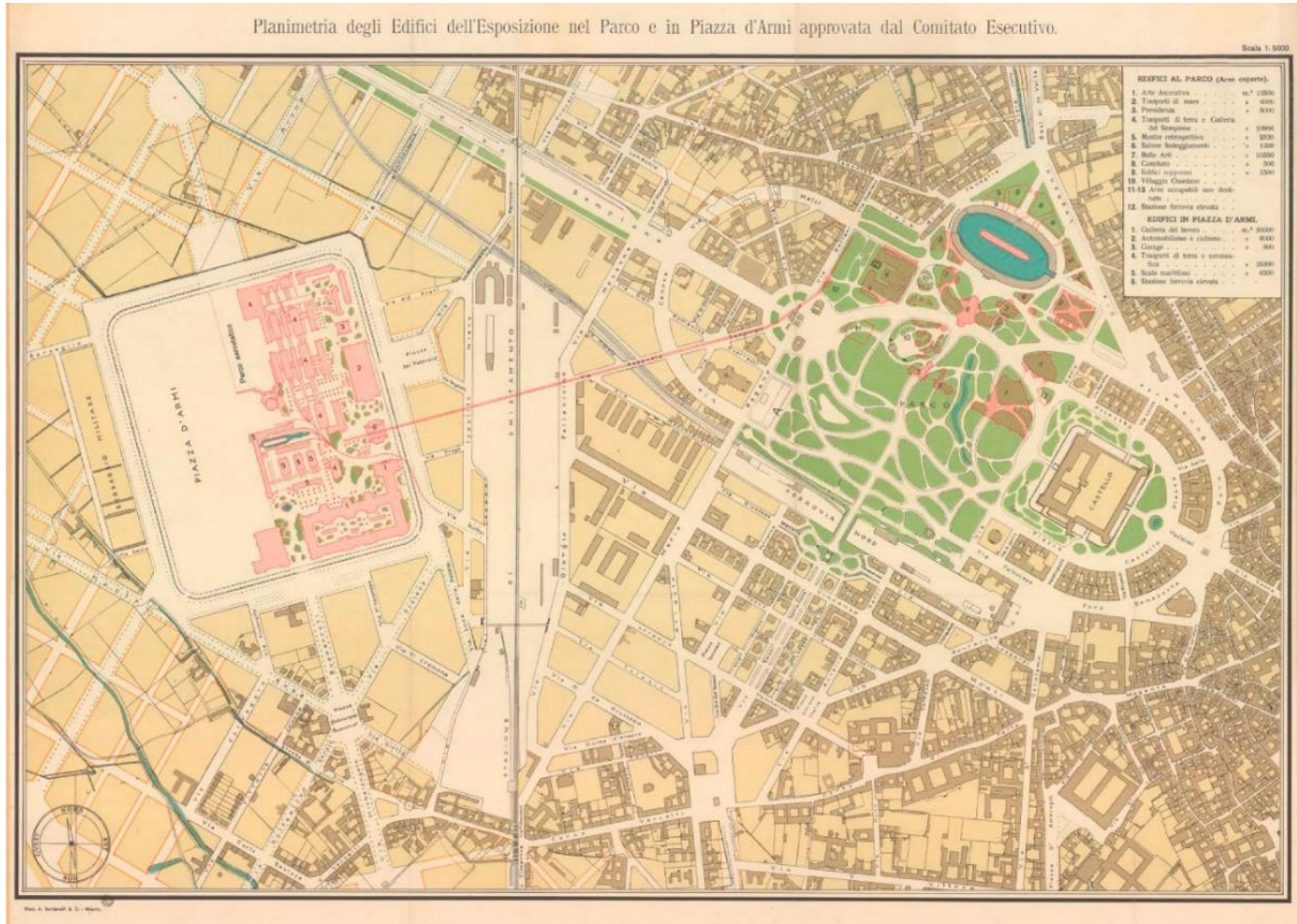

Fuente: Archivo municipal del Ayuntamiento de Milán "Raccolta delle Stampe Achille Bertarelli")

Una vez asumidas estas pautas de desarrollo urbano, que se encaminaban hacia la dispersión urbana, es cuando se piensa desplazar, una vez más, la Plaza de Armas hacia unos terrenos extraurbanos pertenecientes al municipio de Baggio ${ }^{5}$, al oeste de Milán. Para lo cual, y como apoyo estratégico, se aprovechó la existencia de un aeródromo para dirigibles, construido en 1907 por la Sociedad "Leonardo da Vinci", cuyo responsable era el ingeniero milanés Enrico Forlanini ${ }^{6}$. Finalmente, la Plaza de Armas se ubicó en Baggio en 1923, coincidiendo con la anexión a la ciudad de Milán de 11 municipios periféricos.

Por esa misma época, en 1922, el Ayuntamiento adquirió los 326.950 m² que comprendía la "gran propiedad militar" desplazada (Colombo, Mocarelli y Stanca, 2003: 19), para construir el conjunto de la Feria de Muestras de la ciudad - Fiera campionaria en italiano-. De esta manera se hace realidad una "área de nueva centralidad" que respondía a las exigencias de una burguesía local, reforzando la internacionalización de Milán, así como también su papel de "centro representativo y económicofinanciero", en el marco del Estado italiano.

\footnotetext{
${ }^{5}$ Para un análisis más detallado de la historia de la evolución del municipio de Baggio, correspondiente a la tercera ubicación de la Plaza de Armas, se remite a la relación histórica de Uberti (2015) proporcionada por la asociación local milanesa "Le Giardiniere" (https://www.legiardinieremilano.it/la-piazza-d-armi/).

${ }^{6}$ El mismo Forlanini estuvo incluso en contacto con el entonces Ministerio de la Guerra para desarrollar algunos proyectos militares, y durante la primera guerra mundial el aeródromo acabó consolidándose como uno de los campos de aterrizaje de los dirigibles italianos.
}

ACE, 16 (4.6) CC BY-ND 3.0 ES | UPC Barcelona, España | Propiedades militares y nuevas áreas de centralidad. El caso de la Plaza de Armas de Milán. DOI: http://dx.doi.org/10.5821/ace.16.46.10366 


\section{Entre la descentralización de los usos militares y el fortalecimiento de la centralidad}

Al hilo del debate surgido en aquella época a propósito de la necesidad de relocalizar, fuera de los centros urbanos, las actividades militares que se encontraban diseminadas por la ciudad (Bruni, 1937; Rigotti, 1938; Melis, 1941; Pagano, 1941), en el caso específico de Milán tomó forma esta proposición creando, como alternativa, una ciudad militar alrededor de una Plaza de Armas localizada en una zona rural. En la zona elegida se localizaba, tal y como hemos indicado, un aeródromo, lo que se consideraba una ventaja para impulsar la presencia militar en dicha zona, cobrando sentido la materialización de la nueva Plaza de Armas. Una vez asumido el antiguo municipio de Baggio como sede ideal para la ciudadela militar, se intentó llevar a cabo un proyecto, durante la época del fascismo, con la finalidad de proceder al desmantelamiento de los edificios militares que se localizaban en el centro de la ciudad, lo que supuso su desplazamiento al lugar que ocupaba la nueva Plaza de Armas que se había vinculado al antiguo aeródromo de Baggio.

El proyecto se ponía como objetivo la desocupación de las áreas centrales para que estuvieran sujetas a las disposiciones del nuevo Plan General de Ordenación Urbanística, cuyo concurso fue lanzado en 1926 (Comune di Milano, 1926), y cuya puesta en marcha hubiera sido estrechamente ligada a la financiación derivada de la venta a operadores inmobiliarios privados de terrenos estatales, en su mayoría ocupados por cuarteles militares. A partir de 1923, con la agregación de los municipios periféricos a aquello de Milán, el Ayuntamiento planteó el desarrollo urbano a través de un esquema policéntrico, descrito por Cesare Chiodi y basado en la construcción, en las zonas de expansión alrededor del casco antiguo, de una serie de grandes complejos monofuncionales (Riboldazzi, 2008)7. En aquella época, en Milán la lógica de este desarrollo urbano era la siguiente: al "vaciar el centro" (estrategia identificable en la atribución del rol exclusivamente terciario a esta parte de la ciudad, representativo del núcleo histórico, con la consecuente realización en la periferia de la residencia de la pequeña burguesía) debería corresponder la construcción, en las áreas de expansión, de una serie de grandes instalaciones de carácter monofuncional, entre las cuales la ciudadela militar. Esta operación, sin embargo, no tuvo el éxito esperado, debido, sobre todo, a razones económicas. Este proyecto planteaba unas acciones claramente especulativas, ya que estaba supeditado a la substitución de los cuarteles centrales, para construir, en su lugar, asentamientos residenciales para la burguesía. Sin embargo, los acuartelamientos del centro de Milán, sobre todo aquellos que ocupaban propiedades derivadas de un uso eclesiástico anterior, al estar vinculados a los dictámenes de la Superintendencia respecto a los Monumentos, bloqueaban algunas de las posibles operaciones de remodelación de los edificios, limitando las operaciones a emprender, e incluso impidiendo la demolición de algunos de los edificios (Torricelli y Rampi, 1990: 883-886; Poli, 2016).

Este nuevo lugar militar, construido en los restos del antiguo aeródromo, fue adquiriendo, con el tiempo, una importancia cada vez mayor. Entre 1929 y 1935 se construyeron alrededor de la Plaza de Armas, cuya superficie era de $356.630 \mathrm{~m}^{2}$, un cuartel de artillería a caballos, llamada Príncipe Eugenio di Savoia (actualmente Santa Bárbara) (Figura 4), con una superficie de $170.140 \mathrm{~m}^{2}$, y los Almacenes Baggio (Figura 5), de unos $100.000 \mathrm{~m}^{2}$.

\footnotetext{
7 Al mismo tiempo, en la ciudad empezaron a aparecer nuevas urbanizaciones monofuncionales, una especie de ciudadelas con una única función. Además de la feria de muestras, con ubicación central, en el extrarradio oriental de Milán se realizaron la ciudad de los estudios (1921-1927) y la ciudad de abastecimiento (città annonaria), mientras que en la parte noroeste de la ciudad se materializó la ciudad deportiva con el Hipódromo (1925) y el estadio de fútbol San Siro (1925-1926). Como consecuencia, entorno a todas estas ciudadelas, surgieron nuevos núcleos habitados. Por una reseña sobre el urbanismo impulsado por el régimen fascista se remite a Franchi y Chiumeo (1972).
}

ACE, 16 (4.6) CC BY-ND 3.0 ES | UPC Barcelona, España | Propiedades militares y nuevas áreas de centralidad. El caso de la Plaza de Armas de Milán. DOI: http://dx.doi.org/10.5821/ace.16.46.10366 


\section{ACE Architecture, City and Environment}

E-ISSN $1886-4805$

Figura 4. Cuartel Santa Bárbara

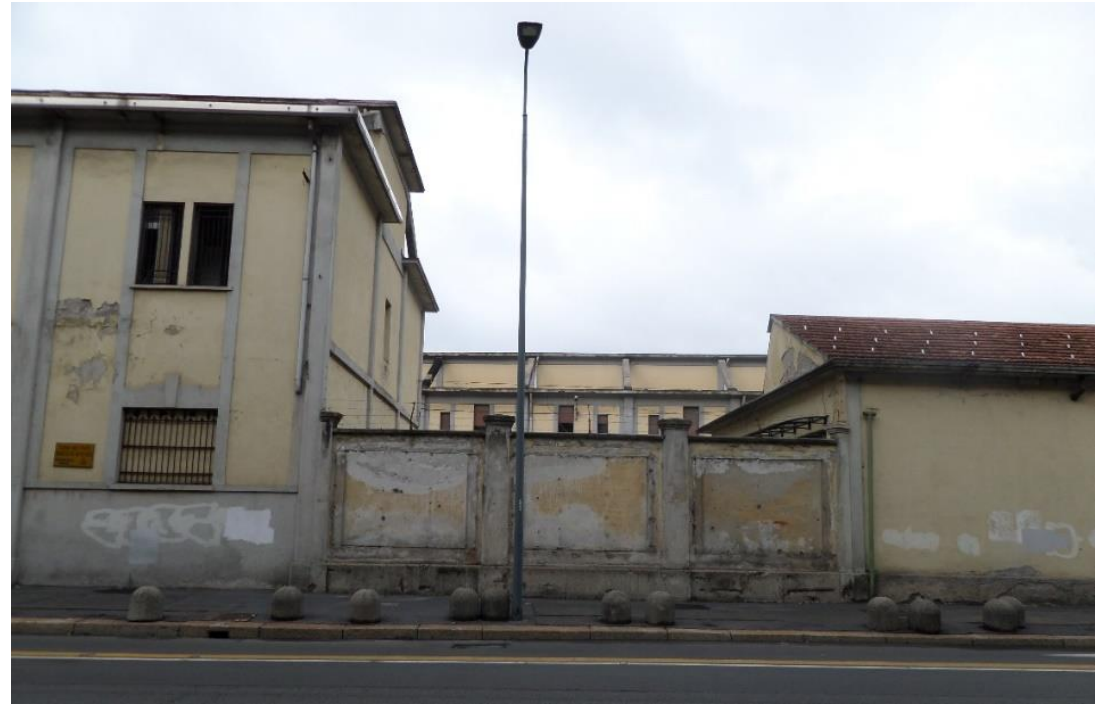

Fuente: Fotografía propia (2017).

En total, nos encontramos con una superficie militar de $618.075 \mathrm{~m}^{2}$. Esta nueva Plaza de Armas se apoyaba en dos ejes viarios históricos de la periferia milanesa, los que, hoy día, se corresponden con las calles Novara y de las Fuerzas Armadas. A esta gran propiedad de suelo militar hay que añadir, muy cerca del lugar que ocupa, un hospital militar, el cuartel Loris Annibaldi (Figura 6), con una superficie de alrededor de $130.000 \mathrm{~m}^{2}$. Es en estos años, los años 30 del siglo pasado, cuando podemos decir que toda esta concentración de propiedades militares, siguiendo la estela de la nueva Plaza de Armas, alcanza su materialización final. Todas las instalaciones surgidas alrededor de esta Plaza han contribuido a conformar un nuevo centro neurálgico militar, tal y como estaba previsto en el proyecto de la ciudadela militar, una de las más importantes realizadas en Italia, por sus dimensiones y por lo que representa como proceso descentralizador de las instalaciones militares que ocupaban el centro de la ciudad (Figura 7).

Figura 5. Almacenes de Baggio

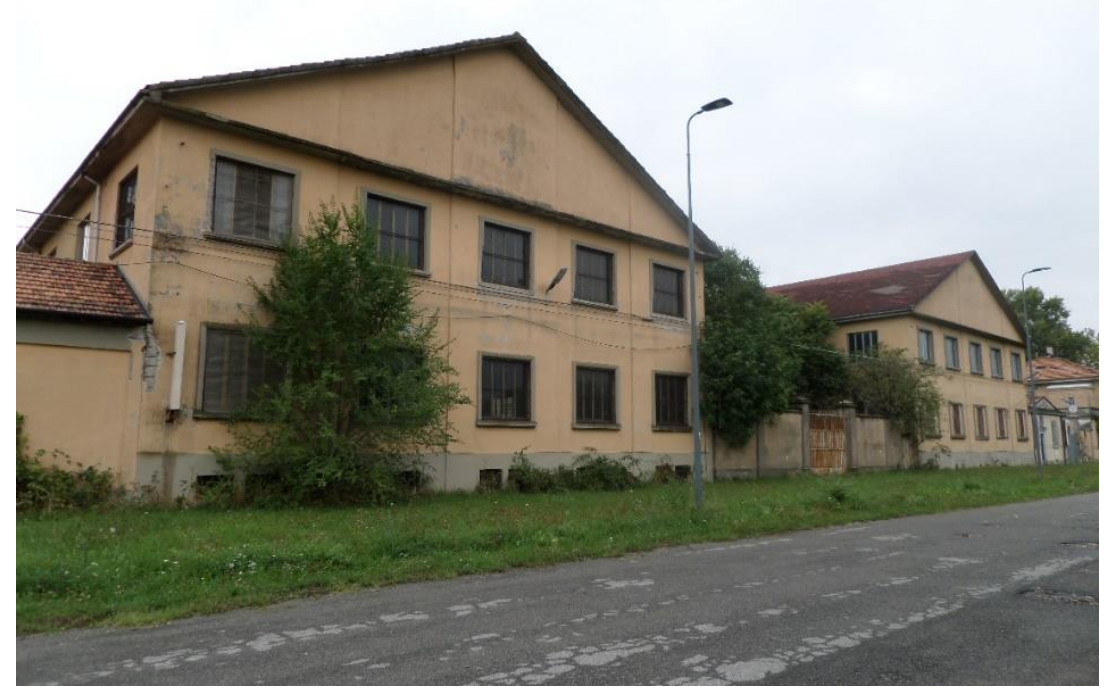

Fuente: Fotografía propia (2017).

ACE, 16 (4.6) CC BY-ND 3.0 ES | UPC Barcelona, España | Propiedades militares y nuevas áreas de centralidad. El caso de la Plaza de Armas de Milán. DOI: http://dx.doi.org/10.5821/ace.16.46.10366 


\section{ACE Architecture, City and Environment}

E-ISSN $1886-4805$

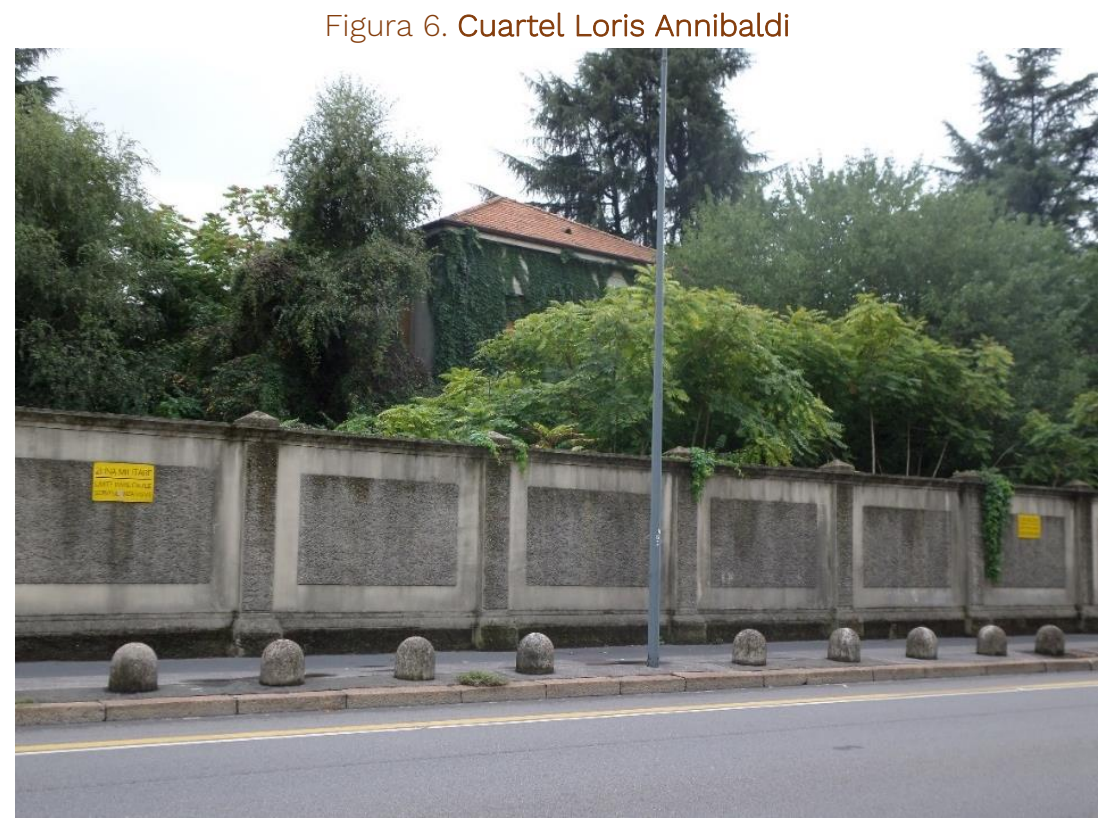

Fuente: fotografía propia (2017).

Figura 7. Ciudad Militar en Baggio

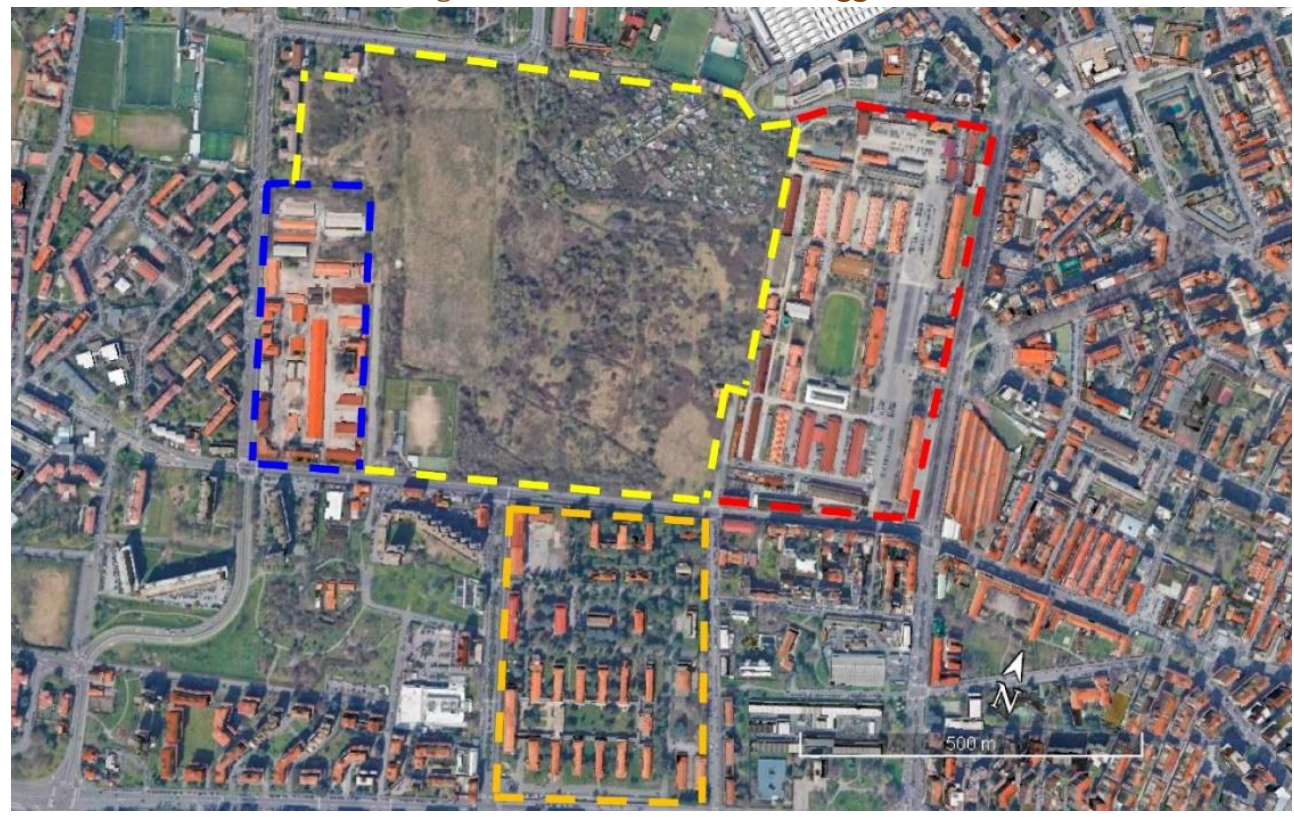

Fuente: Elaboración propia (2021) a partir de ortofotografía de 2021. Localización de los almacenes Baggio (en azul), Plaza de Armas (en amarillo), cuartel Santa Bárbara (en rojo) y cuartel Loris Annibaldi (en naranja).

La actividad militar allí presente seguirá en pleno funcionamiento hasta la década de los 80, cuando la Plaza de Armas, utilizada hasta entonces como campo de maniobra y entrenamiento de los militares, sea objeto de abandono. A ello contribuyó, entre otras cosas, el paulatino desarrollo de un bosque espontaneo, con fauna y flora, en paralelo a un proceso de apropiación no autorizada de algunas de sus zonas, por parte de grupos de ciudadanos, quienes procedieron a cultivar algunos huertos, mientras otros lo convirtieron en asiento espacial de sus viviendas marginales, de chabolas. Tampoco faltó, la presencia de un "basurero" al aire libre.

ACE, 16 (46) CC BY-ND 3.0 ES | UPC Barcelona, España | Propiedades militares y nuevas áreas de centralidad. El caso de la Plaza de Armas de Milán. DOI: http://dx.doi.org/10.5821/ace.16.46.10366 


\section{Del abandono militar a una posible nueva centralidad}

La nueva área militar, conformada en el municipio periférico de Baggio, no se libró del mismo modo que sucedió con las instalaciones militares que se encontraban en el centro de Milán. Este proceso de abandono, desmantelamiento, y vaciamiento, que afectó al área de los Almacenes Baggio-Plaza de Armas, obedeció a varios factores, los cuales no respondieron, únicamente, a los cambios que se estaban produciendo en la dinámica propia del aparato militar, desde el momento en que ya no se requería la presencia de una Plaza de Armas en territorio milanés. El abandono de esta Plaza de Armas como área para el entrenamiento y maniobras, así como el desmantelamiento, en paralelo, de los Almacenes de Baggio, a partir de la década de 1980, a lo que habría que añadir, además, la paulatina infrautilización de que fue objeto el cuartel Santa Bárbara, desde el año 2000, se enmarca, en cierta manera, en la eliminación del servicio militar obligatorio.

Sin embargo, el factor desencadenante de este proceso de abandono y desmantelamiento, remite a específicas dinámicas urbanas, a la forma de proceder al proceso de producción de la ciudad. Las exigencias derivadas del desarrollo urbano, protagonizado por la ciudad de Milán, han tenido una importancia relevante en el abandono que emprendieron el conjunto de las grandes propiedades de suelo militar. Todo ello, por diferentes razones, las cuales están muy relacionadas entre sí. En primer lugar, la manera de proceder al desarrollo urbano de la ciudad de Milán, desde una óptica ilimitada, sobre todo a partir de la década de 1950 (Oliva, 2002), lo que supuso la paulatina urbanización del área vinculada con la antigua ciudad militar. En pocos años, dicho "desarrollo urbano ilimitado" ha ido engullendo, materialmente, las instalaciones militares, perdiendo éstas su carácter periférico, para pasar a formar parte de la ciudad construida.

En segundo lugar, la implementación de una nueva jerarquía de centralidades, las cuales han ido perfilando una nueva idea de ciudad. Fenómeno que comenzó a manifestarse, en Milán, a partir de los años 80 del siglo pasado, lo que ha provocado un cambio en las relaciones espaciales que mantenían las diferentes partes de la ciudad, sobre todo entre la ciudad y su territorio inmediato (Bonomi y Abruzzese, 2004; Morandi, 2005). Se trata de un territorio que, desde finales de los años 70 del siglo pasado, ya no se define por su compacidad, en el marco de sus confines municipales, sino por su condición como realidad espacial dispersa, a lo que hay que añadir sus tendencias metropolitanas, lo que lo convierte en un polo atrayente para inversiones, sobre todo las provenientes del capital inmobiliario-financiero (Aa. Vv., 2005). Las operaciones de regeneración urbana a las que con posterioridad ha sido sometida la ciudad, responden, por otro lado, a una lógica de desregulación urbanística nacida de acuerdos públicos-privados que garantizasen la producción de la renta urbana diferencial (Campos Venuti, 1993; Bolocan Goldstein y Bonfantini, 2007; Bottini y Gibelli, 2012). Es esta estrategia la que ha proporcionado toda su lógica a la conformación de un nuevo modelo urbano basado en la instauración de un sistema de centralidades que recorre todo el territorio de la ciudad (Garofoli y Magnani, 1992). Nuevas centralidades para cuya consolidación ha sido necesario disponer del patrimonio existente heredado, periférico o central, para lo cual resultaba imprescindible proceder a su regeneración, o puesta en valor. Patrimonio identificado con las instalaciones militares, así como también con actividades industriales y ferroviarias, vinculadas, estas últimas, a un sistema económico fordista que estaba siendo sustituido por un capitalismo cada vez menos interesado por el trabajo y más por la obtención de beneficios a unos costes cada vez más bajos, casi sin salarios, si ello fuese posible. De esta forma es como desaparecen las viejas estructuras socio-espaciales, de signo, decimos, fordista, para dar paso a los nuevos iconos del poder desde las regeneraciones urbanas emprendidas (Sklair, 2017). Valga como ejemplo el proceso seguido por la antigua feria de muestras,

ACE, 16 (46) CC BY-ND 3.0 ES | UPC Barcelona, España | Propiedades militares y nuevas áreas de centralidad. El caso de la Plaza de Armas de Milán. DOI: http://dx.doi.org/10.5821/ace.16.46.10366 
objeto de un proyecto de regeneración urbana, denominado CityLife ${ }^{8}$, cuyos objetivos se vinculan con el fenómeno del ocio-consumo, lo que se ha manifestado a través de centros direccionales, residencias a alto standing, etc., adoptándose como expresión final, como no podía ser de otra manera, la que se identifica con una alta edificabilidad, aquella que despliegan los rascacielos de turno. Hoy día este proyecto urbano se ha convertido en el imaginario milanés en el nuevo centro urbano de la ciudad, representativo del definitivo salto de Milán hacía una dimensión global de lo urbano. Sin embargo, en la lectura global de las transformaciones llevadas a cabo sobre las grandes propiedades de suelo, no todos los proyectos planteados han sido realizados.

En tercer lugar, como factor desencadenante de los procesos de abandono, hacemos referencia al desarrollo del modelo urbano segregado, fortalecido con un proceso paralelo de dispersión socioespacial (Tosi, 2017), el cual se ha manifestado en la zona de Baggio, entre otras cosas, desde la concentración, en dicho lugar, de "viviendas protegidas", lo que produce un "proceso de guetización", así como un cierto riesgo de marginación social, vinculado, todo ello, a la presencia en esta zona de un importante contingente de inmigrantes, y de una población de escasos recursos (Foot: 2003: 72). Todo eso, a pesar de que este ámbito se caracterice por una buena dotación de equipamientos urbanos bien conectados entre sí a través del "sistema infraestructural metropolitano".

Estos tres factores son los han contribuido -ésta es la hipótesis - al abandono y vaciamiento del distrito militar en cuestión, poniendo en valor este gran espacio, así como también sus zonas adyacentes, como área apta para que se desarrolle un proyecto de "regeneración urbana" que responda, en teoría, a las cuestiones a resolver detectadas en Baggio.

\section{La realización final del proceso de gestión de la regeneración urbana emprendida}

En 2005 fue cuando comenzó, oficialmente, a ponerse en marcha el lento proceso que acabará transformando el conjunto Almacenes Baggio-Plaza de Armas. La caracterización de sus terrenos, desde el Decreto de enajenación de 28 de febrero de 2005 (Ministero della Difesa, 2005), supuso una declaración oficial, por parte de los militares, quienes argumentaban la inutilidad de aquellas instalaciones para los fines institucionales del Ministerio de Defensa. Por ello exigían su entrega a la Agencia del Dominio Público ${ }^{9}$, con el objetivo proceder a su enajenación para beneficio de las finanzas del Estado, también del Ministerio de Defensa. Siguiendo las determinaciones de este dispositivo normativo, el protocolo de colaboración interinstitucional entre Ministerio de Defensa y Ayuntamiento de Milán, planteó, en mayo de 2009, una operación tendente a racionalizar y "regenerar" nueve sitios militares localizados en la capital de Lombardía. Su superficie total era de unos $918.899 \mathrm{~m}^{2}$ (Comune di Milano, 2012a: 3). De las nueve instalaciones, seis de ellas se tramitaron como "operaciones prioritarias". Se trataba de los cuarteles Mameli, Mercanti y Montello, el conjunto Almacenes de Baggio-Plaza de Armas-cuartel Santa Bárbara y el distrito militar compuesto por los cuarteles XXIV Maggio-Carroccio-Magenta (Figura 8).

\footnotetext{
${ }^{8}$ CityLife (https://www.city-life.it/) es el proyecto de recualificación de la feria de muestras, la cual había sido realizada en el segundo emplazamiento de la Plaza de Armas (véanse Figura 1).

${ }^{9}$ La Agencia del Dominio Público italiana (Agenzia del Demanio en italiano) es el ente público italiano responsable de la gestión, racionalización y puesta en valor del patrimonio inmobiliario estatal y de otros entes públicos (https://www.agenziademanio.it/opencms/it/).
}

ACE, 16 (4.6) CC BY-ND 3.0 ES | UPC Barcelona, España | Propiedades militares y nuevas áreas de centralidad. El 12 caso de la Plaza de Armas de Milán. DOI: http://dx.doi.org/10.5821/ace.16.46.10366 
Figura 8. Localización de las operaciones prioritarias para la reconversión de los sitios militares

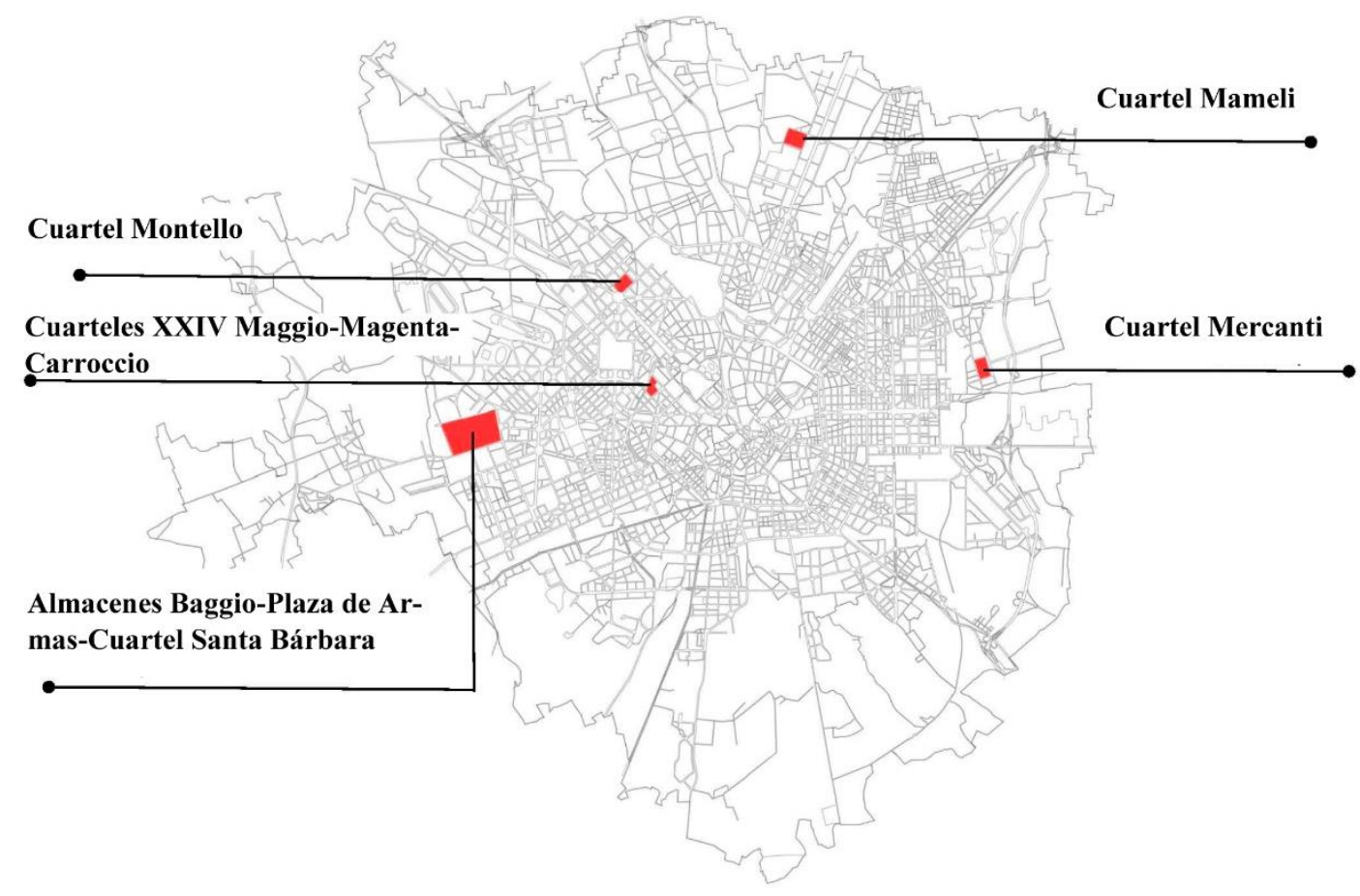

Fuente: Elaboración propia (2021).

Las instalaciones individualizadas, para llevar a cabo estos "proyectos prioritarios", se incluyeron en el Decreto Directoral n. 1/2/5/2010 de 5 de marzo de 2010 (Ministero della Difesa, 2010), para que fuesen transferidas a la Agenzia del Demanio, siguiendo las indicaciones del artículo 14-bis, apartado 3, del D. L. n. 112/2008, más tarde, Ley n. 133/2008. Esto significaba que la Agencia tendría que encargarse, en lugar del Ministerio de Defensa, de la gestión de la operación emprendida. Todo eso, para consentir, en primer lugar, el cambio de uso, en el marco del Plan Regulador y, en segundo lugar, para poder enajenar dichos cuarteles con el consentimiento del Ayuntamiento. Se creaba, en este sentido, cierta incertidumbre, debido a la participación de la Agencia en el procedimiento, lo que daría lugar, más adelante, a que el protocolo de 2009 caducase, planteándose la necesidad de suscribir uno nuevo, hecho que se llevó a cabo en 2014.

Por otro lado, la legislación en materia de enajenación de los bienes militares, así como sus instrumentos actuación, se modificaron para adaptarla a la Planificación Urbana Local. La operación de regeneración, aunque fue emprendida en 2009, se apoyó, más tarde, en el nuevo Plan Regulador de Milán, aprobado el 4 de febrero de 2011, el llamado "Plan de Gobierno del Territorio" (Piano di Governo del Territorio, P.G.T.), el cual clasificaba las áreas militares, las de actuación prioritaria, dentro de la categoría de "ámbito de transformación urbana", de acuerdo con los estudios preliminares realizados, conjuntamente, entre la Administración Local, Defensa y la Dirección Regional para los Bienes Culturales. Como consecuencia del estudio realizado sobre los cuarteles existentes, en el bloque formado por los Almacenes-Plaza de Armas se aprecia solamente un edificio digno de ser conservado, el que está localizado a la entrada de los mismos Almacenes (Comune di Milano, 2012a: 32). Otro cambio de rumbo en la gestión del proceso de "abandono-regeneración" de estos cuarteles, hace referencia a la supeditación de los Almacenes de Baggio-Plaza de Armas al Decreto Directoral n. 88/2/5/2012, de 24 de agosto de 2012, para poder transferirlos definitivamente a la Agenzia y, acto seguido, a un fondo de inversión inmobiliario.

ACE, 16 (4.6) CC BY-ND 3.0 ES | UPC Barcelona, España | Propiedades militares y nuevas áreas de centralidad. El caso de la Plaza de Armas de Milán. DOI: http://dx.doi.org/10.5821/ace.16.46.10366 
Esta fase fue clave para llevar a cabo otro protocolo de colaboración, en agosto de 2014, que supuso la colaboración entre la Agencia del Dominio Público, el Ayuntamiento y Defensa, posibilitando la actuación de dos operaciones (Aa. Vv., 2014), sobre el cuartel Mameli (Montedoro, 2016) y la instalación militar objeto de investigación. En este contexto, el Plan Urbanístico Local define a este sector como "ámbito de transformación urbana”, el identificado por los Almacenes Baggio-Plaza de Armas, determinando que sus usos deberían estar relacionados con el deporte y las actividades de ocio ${ }^{10}$. El Plan Regulador de 2012 (Figura 4), por su parte, preveía, aplicando una edificabilidad de 0,70 $\mathrm{m}^{2} / \mathrm{m}^{2}$, y una superficie construida máxima de $432.652 \mathrm{~m}^{2}$, que una mitad de la misma se destinase a equipamientos y viviendas públicas, ambas de $216.326 \mathrm{~m}^{2}$, mientras que la otra mitad del área total de la antigua instalación militar se destinaría a verde público, unos $309.037 \mathrm{~m}^{2}$ de superficie (Comune di Milano, 2012b: 19-20; Municipio 7, 2017b).

Una vez transferida la titularidad de los Almacenes Baggio-Plaza de Armas, del Ministerio de Defensa a la Agencia del Dominio Público, siguiendo la Ley n. 135/2012, cambio sustancial para proceder a su venta posterior, en julio de 2016, al Fondo i3-Sviluppo Italia Comparto 8-Quater de Invimit ${ }^{11}$, entra en escena, a partir de finales de 2017, un nuevo agente emprendedor. Se trata del club de fútbol Inter, cuyas intenciones estaban centradas en la construcción de su nueva sede deportiva y campos de entrenamiento de fútbol, abandonando el por entonces Pinetina, que se encontraba en Appiano Gentile, provincia de Como. Es así como se genera un debate en torno a las previsiones establecidas en el marco de la Planificación Urbana. El hecho de haber previsto un proyecto urbano con vertiente deportiva y de ocio, suponía modificar las Directrices de la Planificación Urbana para permitir el paso de grandes volúmenes previstos en un principio, a la privatización de esos mismos espacios, pero para materializar espacios públicos, culminando los campos de fútbol proyectados. Este hecho, sin embargo, no tiene ningún tipo de repercusión oficial, lo cual se debe a dos factores. Primero, a la definitiva renuncia, por parte del Inter, de seguir adelante con el proyecto de su nueva sede. No obstante, una licitación para la venta de la propiedad por parte de Invimit en marzo de 2018, en mayo del mismo año no se presenta ningún comprador. La sociedad de fútbol F.C. Inter declara que, debido a las condiciones impuestas en la adquisición, es decir el hacerse cargo del coste total de las operaciones de saneamiento y de reconversión de la entera área, su indisponibilidad en proceder a la compra (Invimit, 2018). En segundo lugar, porque la Comisión especial Plaza de Armas, creada por parte del Distrito 7 del Ayuntamiento de Milán, en enero de 2017 (Municipio 7, 2017a: 30), rechaza las perspectivas de edificación previstas en el área, oponiéndose a su actuación, incluso, ante la Comisión Europea, en enero de 2019. Los comités de protestas (entre los cuales destacan la Associazione Parco Piazza d'Armi Le Giardiniere, Italia Nostra, y Possibile), que se oponían a la "regeneración" de la antigua instalación militar, están promoviendo, por su parte, un debate a nivel internacional a propósito de las alternativas posibles para la puesta en marcha de un proyecto de restitución de los Almacenes Baggio-Plaza de Armas a la sociedad civil.

De hecho, este enfoque para preservar los espacios verdes de la antigua Plaza de Armas, ha sido incluido en la reciente revisión del P.G.T.12. En esta revisión se advierte una posición clara a favor de

\footnotetext{
10 Para cada ámbito de transformación urbana, el P.G.T., de acuerdo con una serie de objetivos, define una cuota de edificabilidad máxima a realizar, atribuyendo un cierto porcentaje del área a funciones públicas para zonas verdes y servicios, remitiéndose, para previsiones más concretas, a la actuación de herramientas urbanísticas de ejecución, como los "acuerdos de programas", accordi di programma en italiano. Substancialmente, el PGT no define de forma contundente las transformaciones a realizar, dejando un amplio espacio de maniobra a los agentes involucrados en la fase de ejecución del proyecto. La actuación de los grandes proyectos urbanos de Milán se ve afectada, de hecho, y en continuidad con el pasado, por la legalización del fenómeno de desregulación por parte de las previsiones del instrumento de planificación urbana.

11 “Investimenti Immobiliari Italiani Sgr S.p.A." (Invimit Sgr) es una sociedad de gestión de activos del Ministerio de Economía y Hacienda italiano cuyo objeto es la prestación de servicios de gestión de activos colectivos mediante la promoción, constitución, organización y gestión de fondos de inversión inmobiliarios. El Fondo i3-Sviluppo Italia Comparto 8-Quater fue instituido en el mayo de 2016 (https://www.invimit.it/).

12 El nuevo P.G.T., llamado "MILANO 2030", se adopta con fecha 5 de marzo de 2019 y se aprueba con fecha 14 de octubre de 2019 (https://www.pgt.comune.milano.it/\#: :text=Il\%20Consiglio\%20comunale\%2C\%20in\%20data,corredato\%
}

ACE, 16 (4.6) CC BY-ND 3.0 ES | UPC Barcelona, España | Propiedades militares y nuevas áreas de centralidad. El 14 caso de la Plaza de Armas de Milán. DOI: http://dx.doi.org/10.5821/ace.16.46.10366 
las necesidades de la ciudadanía, en la regeneración urbana de los Almacenes Baggio-Plaza de Armas. En la Memoria del Plan se afirma que la antigua instalación militar, debido a su condición de vacío urbano de grandes dimensiones, a su accesibilidad, localización y conformación, es compatible con una destinación de uso apta para albergar funciones de carácter estratégico, "de uso público y/o de interés público o general, también privadas [...] para permitir el aumento de funciones de excelencia y, en general, de la capacidad atractiva de la ciudad a escala global» (Comune di Milano, 2018: 63). Y, todo ello, en una lógica de integración con otros grandes proyectos urbanos y metropolitanos que se están materializando. Además, la inclusión de esta área en el más amplio concepto de "gran función urbana", hace que disminuya, automáticamente, su aprovechamiento urbanístico, su edificabilidad prevista, pasando de $0,70 \mathrm{~m}^{2} / \mathrm{m}^{2}$ a $0,35 \mathrm{~m}^{2} / \mathrm{m}^{2}$, considerándose, además, como lugar apto para poner en marcha una operación de forestación urbana. Entre 2018 y 2019, después de haber liberado el conjunto Almacenes Baggio-Plaza de Armas de las ocupaciones abusivas que proponía su propietario (Invimit spa), se impulsó un debate sobre una previsión de demolición, dada la ruina en la que estaban sumidos los edificios que lo componían. El Concejal de Urbanismo, Pierfrancesco Maran (2019), dejaba clara la posición del Ayuntamiento, contraria a la instancia promovida por las asociaciones locales, las cuales en marzo de $2019^{13}$ pedían que el área de los Almacenes de Baggio fuese declarada como bien cultural a proteger. En octubre de 2019, la Superintendencia de Bienes Culturales de Lombardía confirmó que solamente uno de los edificios existentes vinculado en $2009^{14}$, el edificio de mando Palazzina di Comando en italiano - tenía valor monumental, dejando así mano libre para la demolición de la mayoría de los edificios de los Almacenes Baggio entre finales de 2019 y comienzos de $2020^{15}$. Actualmente, a mediados de 2021, el proyecto de reconversión está en fase de estancamiento debido a la crisis derivada de la COVID-1916. Las asociaciones locales están reclamando que la regeneración de este vacío se inserte en las acciones a emprender para la reorganización de la ciudad post-COVID19 dentro de las estrategias de planificación urbana de la ciudad (Le Giardiniere Milano, 2020). La perspectiva de la Milán post-COVID-19 es que se realicen espacios más saludables e inclusivos para todos $^{17}$ apoyada a una movilidad más sostenible ${ }^{18}$, pero evitando un fenómeno de polarización social y de gentrificación de esta zona de la capital milanesa que se compone prevalentemente de edilicia residencial pública.

\section{Conclusiones}

A modo de resumen, podemos decir que el proceso de construcción de la ciudad, a partir del análisis de la Plaza de Armas de Milán, responde a un modelo de desarrollo urbano que se caracteriza por la paulatina pérdida de compacidad de su espacio urbano tradicional, a favor de la "dispersión" territorial, acompañado, todo ello, de la progresiva urbanización del territorio extraurbano. Procesos que no tienen otro objetivo que favorecer los intereses del capital desde la producción de renta urbana a partir de la gestión y explotación de la gran propiedad, entendida ésta como capital fijo en suelo. Este ha sido el leitmotiv que ha acompañado a las "transformaciones urbanas" que han tenido lugar en una ciudad como Milán. Ciudad en la que se han llevado a cabo grandes proyectos de "regeneración urbana que se han apoyado en las posibilidades de gestión que presentaban los ámbitos industriales y ferroviarios declarados obsoletos, considerando dichos artefactos el terreno perfecto desde el que implementar estrategias de desarrollo urbano, en colaboración con los promotores inmobiliarios privados interesados, incluso siendo ellos mismos propietarios de las áreas en cuestión.

20dal\%20nuovo\%20studio\%20geologico)

${ }^{13}$ https://www.legiardinieremilano.it/app/download/15540032522/richiestariesameSovrintendenzater.pdf?t=1611764717

14 https://www.lombardiabeniculturali.it/architetture/schede/LMD80-00842/

15 https://blog.urbanfile.org/2020/10/07/milano-forze-armate-piazza-darmi-e-la-caserma-fine-settembre-2020/

16 https://www.comune.milano.it/web/municipio-7/municipio/commissioni/commissione-n.-10-a-termine-piazza-d-armi

17 https://www.comune.milano.it/aree-tematiche/partecipazione/milano-2020

18 https://rue-avenir.ch/wp-content/uploads/2020/05/Strade-Aperte-Milan-2020.pdf

ACE, 16 (4.6) CC BY-ND 3.0 ES | UPC Barcelona, España | Propiedades militares y nuevas áreas de centralidad. El 15 caso de la Plaza de Armas de Milán. DOI: http://dx.doi.org/10.5821/ace.16.46.10366 
La redistribución espacial de determinadas actividades vinculadas con la vida urbana, como es el caso de las ferroviarias, industriales e incluso militares, localizadas, en origen, en estrecha conexión con la ciudad existente-construida, ha provocado la dispersión territorial de la urbanización, la redistribución de la población y la pérdida de complejidad que caracterizaba el espacio urbano tradicional compacto. Todo ello ha desembocado en el proceso de construcción y consolidación, a lo largo del tiempo, de la periferia urbana como nuevo espacio social, en contraposición con lo que estaba sucediendo en el antiguo centro urbano de la ciudad.

Por lo que respecta a la Plaza de Armas, su continua relocalización, en el contexto de la ciudad de Milán, ha contribuido a la extensión territorial de la ciudad, es decir, a la creación de nuevas periferias que, con el paso del tiempo, han consolidado su condición de espacios marginales, aunque han ido vinculándose, atendiendo a su diversificación social, asumiendo o superando su original marginación, a las nuevas áreas de centralidad que han ido materializándose a lo largo y a lo ancho de la ciudad. Es el caso de la zona de Baggio, incorporada al municipio de Milán en los años 20 del siglo pasado, la cual protagonizó una rápida urbanización, sobre todo después de 1945. Esta dinámica inmobiliaria expansiva ha supuesto su caracterización como barrio obrero, equipado, eso sí, con servicios urbanos de cierta calidad, lo que ha constituido, posiblemente, la base material para impulsar, a posteriori, procesos de regeneración, apostándose por la práctica de la desposesión espacial de clase.

En el proceso de abandono-desmantelamiento y regeneración de los Almacenes Baggio-Plaza de Armas, observamos cómo el proceso específico de producción histórica de este barrio, acumulando cualidades creadas colectivamente, ha ido acumulando las condiciones básicas para emprender una operación de transformación urbana de gran impacto a nivel territorial. Las intervenciones planteadas, sobre la base de las grandes propiedades militares milanesas, apoyándose en los mecanismos de regulación normativos, legislados por el Estado italiano, e introducidos como determinaciones urbanísticas en la Planificación, han contemplado, en un primer protocolo de colaboración de 2009, una serie de áreas, abandonadas e infrautilizadas, cuya transformación se ha verificado siguiendo específicas vicisitudes normativas, políticas y urbanísticas (Neri, 2014; Montedoro, 2016; Pugliese, 2016). El fomento de la exclusividad y la excelencia del lugar, sobre la base de un bien de titularidad pública que se ha privatizado, se conforma como el leitmotiv que, desde hace cuatro décadas, ha conducido los procesos de regeneración urbana en Milán (Armondi y Di Vita, 2017).

Una posible brecha en los intereses del capital inmobiliario-financiero podría producirse a través de la revisión del Plan Regulador General de Milán, el cual acaba de publicarse. La disminución de la edificabilidad, procediendo en paralelo a lo que podríamos denominar como forestación urbana, y apoyado por la acción de los comités locales, pueden convertirse en las bases sobre las que impulsar un proyecto que tenga como objetivo la materialización de un parque urbano de gran alcance que sirva de elemento para resolver los problemas de guetización y marginalización social que están afectando esta zona de la capital milanesa (Tacchi, 2010), cuya componente social remite a la clase obrera de la Milán fordista (Foot, 1997: 639-643).

Este análisis histórico que culmina en la discusión entre los dos planes-propuestas para el lugar que ocupa la última Plaza de Armas, parece que se basa en una reducción de edificabilidad, implícitamente considerando que ello ya le ofrece mayor calidad y mejor cumplir el bien común o interés general. ¿Se identifica con menor construcción? ¿No será este posicionamiento contradictorio con la aparente denostación de la dispersión y la ciudad difusa? El abandono de las instalaciones militares parece responder a un proceso de transformación de sus papel y condición (profesional) con instalaciones ad hoc, más específicas. Es una cuestión recurrente frente a los procesos de obsolescencia tanto de los usos como de su localización relativa en las metrópolis.

ACE, 16 (4.6) CC BY-ND 3.0 ES | UPC Barcelona, España | Propiedades militares y nuevas áreas de centralidad. El caso de la Plaza de Armas de Milán. DOI: http://dx.doi.org/10.5821/ace.16.46.10366 
Finalmente, lo que aporta este estudio es un análisis que pone en luz las dinámicas urbanas e inmobiliarias del proceso de construcción histórico de la ciudad de Milán en estricta relación con el continuo emplazamiento-desplazamiento de las Plazas de Armas, desde su construcción primitiva, hasta su abandono definitivo, y las directrices de los instrumentos de planificación urbana. Este trabajo se constituye como una especie de estudio primordial para aplicar a otros casos, italianos y extranjeros, para suplir las lagunas de investigación en el tema de la enajenación y reutilización de grandes propiedades militares desde la unificación del estado italiano hasta la actualidad que pueden contribuir al entendimiento de la evolución de la ciudad. El tema de las áreas militares nunca ha sido adecuadamente examinado debido a varias restricciones en el acceso a la información ${ }^{19}$. La falta de análisis se evidencia, sobre todo, por lo que respecta a las implicaciones de las propiedades militares con la gestión de la ciudad, así como en su consideración con los resultados de las políticas públicas que se han implementado para favorecer la reconversión de las zonas militares, sin olvidar otros tipos de políticas urbanas, aquellas que están más implicadas con cuestiones financieras. Efectivamente, salvando las distancias, se necesitaría un análisis pormenorizado en casos parecidos, que son múltiples en las realidades italianas, así como en otras europeas. A modo de ejemplo, un caso que se está destacando por la forma de proceder en la intervención en la ciudad contemporánea (Bajo Martínez de Murguía, 2021), sobre todo en el proceso de toma de decisiones y reutilización temporánea, es el del antiguo cuartel militar periférico de Son Busquets $\left(110.865 \mathrm{~m}^{2}\right.$ ), en la ciudad mediterránea de Palma (Mallorca), último gran vacío urbano para el que se prevé su regeneración y reinterpretación urbanística mediante la construcción de viviendas de protección oficial y espacios libres verdes (Gené y Alomar-Garau, 2020; Alomar-Garau, 2021).

\section{Agradecimientos}

Este artículo es fruto del trabajo realizado dentro del proyecto European Joint Doctorate "urbanHIST". European Union. This project has received funding from the European Union's Horizon 2020 research and innovation programme under the Marie Sktodowska-Curie grant agreement No 721933

Conflicto de intereses: El autor declara que no hay conflicto de intereses.

\section{Bibliografía}

Aa. Vv. (1989). Esercito e città. Dall'Unità agli anni Trenta. Atti del Convegno di studi (Perugia, 11-14 maggio 1988). Tomo I, Tomo I/. Roma, Italia: Ministero per i beni culturali e ambientali.

Aa. Vv. (2005). Milano nodo della rete globale. Un itinerario di analisi e proposte. Milán, Italia: Bruno Mondadori.

Aa. Vv. (2014). Protocollo d'intesa tra Ministero della Difesa, Comune di Milano e Agenzia del Demanio per la razionalizzazione e valorizzazione di alcuni immobili militari presenti nel territorio comunale. Recuperado de https://www.comune.milano.it/dseserver/webcity/comunicati.nsf/d68aa3 e55927f9f7c1256c4500573452/b4b8677cdad6b669c1257d2d00492e09/\$FILE/FILE\%203 MILANO 07 \%20AGOSTO\%202014.pptx

Addison, F. y Artioli, F. (2020). Four types of urban austerity: Public land privatisations in French and Italian cities. Urban Studies, 57(1), 75-92. DOI: https://doi.org/10.1177/0042098019827517

Aguilar, I. et al. (Eds.). (1980). Las estaciones ferroviarias de Madrid. Su arquitectura e incidencia en el desarrollo de la ciudad. Madrid, España: Colegio oficial de arquitectos de Madrid.

\footnotetext{
19 Que hasta hace unos años impedían el acceso físico dentro del recinto que circunscribe un área militar y a la historia "documental" de los artefactos y de las características técnico-constructivas de los edificios.
}

ACE, 16 (4.6) CC BY-ND 3.0 ES | UPC Barcelona, España | Propiedades militares y nuevas áreas de centralidad. El 17 caso de la Plaza de Armas de Milán. DOI: http://dx.doi.org/10.5821/ace.16.46.10366 
Alomar-Garau, G. (2021). Urbanismo crítico, cartografía y evolución del verde urbano en los planes de ensanche históricos de la ciudad de Palma (Mallorca). ACE: Arquitectura, Ciudad y Entorno, 15(45), 9039. DOI: http://dx.doi.org/10.5821/ace.15.45.9039

Álvarez Mora, A. (1979). Madrid. Las transformaciones del Centro-Ciudad en el Modo de Producción Capitalista. Madrid, España: COAM.

Álvarez Mora, A. (1996). La necesaria componente espacial en la Historia Urbana. Ayer, 23, 29-60.

Álvarez Mora, A. (2004). Modelos de desarrollo urbano. De la ciudad compacta al metropolitano disperso. En A. Álvarez Mora y F. Valverde Díaz de León (Eds.), Ciudad, territorio y patrimonio. Materiales de investigación // (pp. 227-261). Puebla de los Ángeles-Valladolid, México-España: Universidad Iberoamericana Puebla-Instituto Universitario de Urbanística, Universidad de Valladolid.

Álvarez Mora, A. (2015). La ciudad como producto versus la ciudad, o la realidad urbana entre el espacio de la renta y el espacio social. Valladolid, España: Universidad UVA de Valladolid.

Antolini, G. A. (1814). Opera d'architettura, ossia, Progetto sul foro che doveva eseguirsi in Milano: in 24 tavole in rame. Milán, Italia: Fratelli Bettalli.

Allocchio, S. (1889). La nuova Milano. Milán, Italia: Hoepli.

Apur (1987). L'aménagement de l'Est de Paris. Paris Projet n. 27-28. París, Francia: Apur.

Armondi, S. y Di Vita, S. (Eds.). (2017). Milan: Productions, Spatial Patterns and Urban Change. Reino Unido-Estados Unidos: Routledge.

Bagaeen, S. y Clark, C. (Eds.). (2016). Sustainable Regeneration of Former Military Sites. Londres-Nueva York, Reino Unido-Estados Unidos: Routledge.

Bajo Martínez de Murguía, F. (2021). Otros procedimientos de intervención en la ciudad contemporánea: sobre la re-densificación. ACE: Architecture, City and Environment, 15(45), 9527. DOI: http://dx.doi.org/10.5821/ace.15.45.9527

Bolocan Goldstein, M. y Bonfantini, B. (Eds.). (2007). Milano incompiuta. Interpretazioni urbanistiche del mutamento. Milán, Italia: Franco Angeli

Bonet Correa, A. (Ed.). (1978). Plan Castro. Madrid, España: COAM.

Bonomi, A. y Abruzzese, A. (Eds.). (2004). La città infinita. Milán, Italia: Bruno Mondadori.

Boriani, M.; Rossari, A. y Rozzi R. (Eds.). (1992). La Milano del piano Beruto (1884-1889). Società, urbanistica e architettura nella seconda metà dell'800. Volume / and Volume II. Milán, Italia: Guerini e Associati.

Botti, G. y Ricci, G. (Eds.). (2011). L'Esposizione Internazionale del Sempione Milano 1906. Catalogo dei disegni di architettura dell'Archivio Storico Civico. Milán, Italia: Archivio Storico Civico e Biblioteca Trivulziana Castello Sforzesco.

Bottini, F. y Gibelli, M. C. (2012). Milán: la difícil herencia de veinte años de desregulación urbanística. Urban, 3, 31-43.

Bruni, N. (1937). Igiene militare. Milán, Italia: Società Editrice Libraria.

Camerin, F. (2010). El papel de la gran propiedad en el proceso de construcción de la ciudad europea durante el último tercio del siglo XX. Las propiedades militares como referente / The role of great property in the european city-making process in the last third ot the 20th century. Military property as reference (Tesis doctoral en co-tutela en doble versión castellano-inglesa). Universidad UVA de valladolid-BUW Weimar, Valladolid-Weimar.

ACE, 16 (46) CC BY-ND 3.0 ES | UPC Barcelona, España | Propiedades militares y nuevas áreas de centralidad. El caso de la Plaza de Armas de Milán. DOI: http://dx.doi.org/10.5821/ace.16.46.10366 
Campos Venuti, G. (1993). Il regime immobiliare in Italia. En Campos Venuti, G.; Oliva F. (Eds.). Cinquant’anni di urbanistica in Italia 1942-1992 (pp. 119-132). Bari-Roma, Italia: Laterza.

Cerdà, I. (1867). Teoría General de la Urbanización y aplicación de sus principios y doctrinas a la Reforma y Ensanche de Barcelona. Madrid, España: Imprenta Española.

Cesa Bianchi, P. (1884). La necessità dello studio di un piano regolatore della città in relazione al Duomo e ai propositi nuovi quartieri in Piazza d'Armi. Milán, Italia: Saldini.

Comune di Milano (1926). Il bando di concorso nazionale per lo studio di un progetto di piano regolatore e d'ampliamento per la città di Milano. Milán, Italia: Comune di Milano.

Comune di Milano (2012a). I Siti Militari studio di fattibilità. Razionalizzazione, accorpamento ed ammodernamento del patrimonio immobiliare in uso al Ministero della Difesa nella città di Milano. Milán, Italia: Comune di Milano. Recuperado de https://docplayer.it/8829413-I-siti-militari-studio-di$\underline{\text { fattibilita.html }}$

Comune di Milano (2012b). Piano di Governo del Territorio. Documento di Piano. Allegato 3 "Schede di indirizzo per l'assetto del territorio" e tabella dati quantitativi. Recuperado de http://download.comune.milano.it/12 02 2015/692e469d-a83e-4709-9fda-26893a64760e.pdf

Comune di Milano (2012c). Piano di Governo del Territorio. Documento di Piano. Allegato 3 "Schede di indirizzo per l'assetto del territorio" e tabella dati quantitativi. Milán: Comune di Milano. Recuperado de: http://download.comune.milano.it/12 02 2015/692e469d-a83e-4709-9fda-26893a64760e.pdf

Comune di Milano (2018). Piano di Governo del Territorio. Documento di piano Milano 2030 Visione, Costruzione, Strategie, Spazi Relazione Generale. Recuperado de http://allegati.comune.milano.it/te rritorio/20181029 PGT Giunta Def/01 Documento Piano/01DP Relazione Generale.pdf

Colombo, E.; Mocarelli, L. y Stanca, L. M. (2003). Il ruolo della fiera di Milano nell'economia italiana. Milán, Italia: Franco Angeli.

D’Amia, G. (2021). Milano capitale 1797-1814. Architetture, monumenti e spazi urbani della città napoleonica. Cinisello Balsamo, Italia: Silvana Editoriale

De Ureña, J. M. (Ed.). (2020). Debate Relaciones entre Proyecto Arquitectónico, Proyecto Urbano y Plan de Ordenación Urbana. Maet 1 Ciudad Magacín de Arquitectura de la Escuela de Toledo. Toledo, España: EAT.

Della Peruta F. (1988). Esercito e società nell'Italia napoleonica. Milán, Italia: Franco Angeli.

Devoti, C. (Ed.). (2018). Gli spazi dei militari e l'urbanistica della città. L'Italia del Nord-ovest (1815-1918). Storia dell'urbanistica n. 10/2018. Roma, Italia: Edizioni Kappa.

Fiorino, D.R. (Ed.). (2017). Military Landscapes. A future for military heritage. Milán, Italia: Skirà.

Foot, J. (1997). Il boom dal basso: famiglia, trasformazione sociale, lavoro, tempo libero e sviluppo alla Bovisa e alla Comasina (Milano), 1950-1970. En S. Musso (Ed.). Tra fabbrica e società: mondi operai nell'talia del Novecento, Volume 33 (pp. 617-649). Milán, Italia: Feltrinelli.

Foot, J. (2003). Milano dopo il miracolo: biografia di una città. Milán, Italia: Feltrinelli.

Franchi, D. y Chiumeo, R. (1972). Urbanistica a Milano in regime fascista. Florencia, Italia: La Nuova Italia

Gaeta, L. y Savoldi, P. (Eds.). (2013). Orientamenti per la gestione del patrimonio immobiliare pubblico. Milán, Italia: Società Italiana degli Urbanisti.

Gaillard, J. (1977). Paris, la Ville 1852-1870. Paris, Francia: l’Harmattan.

Garofoli, G. y Magnani, I. (Eds.) (1992). Verso una nuova centralità delle aree urbane nello sviluppo dell'occupazione. Milán, Italia: Franco Angeli.

ACE, 16 (4.6) CC BY-ND 3.0 ES | UPC Barcelona, España | Propiedades militares y nuevas áreas de centralidad. El caso de la Plaza de Armas de Milán. DOI: http://dx.doi.org/10.5821/ace.16.46.10366 
Gastaldi, F. y Camerin, F. (2019). Aree militari dismesse e rigenerazione urbana. Potenzialità di valorizzazione del territorio, innovazioni legislative e di processo. Siracusa, Italia: Letteraventidue

Gené Gil, L. y Alomar-Garau, G. (2020). Son Busquets (Palma, Mallorca): un caso de urbanismo participativo para un nuevo modelo de ciudad. En C. Llop, M. Cervera y F. Peremiquel (Eds.), IV Congreso ISUF-H: Metrópolis en recomposición: prospectivas proyectuales en el Siglo XXI: Forma urbis y territorios metropolitanos. Barcelona, 28-30 septiembre 2020 (pp. 1-18). Barcelona: DUOT, UPC. Recuperado de http://hdl.handle.net/2117/328613.

Invimit (2018). Piazza d'Armi a Milano: Ferrarese, noi rilanciamo. Recuperado de https://www.invimit.it/piazza-darmi-a-milano-ferrarese-noi-rilanciam/.

Le Giardiniere Milano (2020). Parco Piazza d’Armi - Milano Strategie di adattamento Milano 2020. Recuperado de https://www.legiardinieremilano.it/app/download/15724101622/RIMANIStrategie+di+adattamento+2020.pdf?t=1591032222.

Macchi Cassia, C. (1991). Il grande progetto urbano. La forma della città e i desideri dei cittadini. Roma, Italia: La Nuova Italia Scientifica.

Maran, P. (2019). Piazza d'armi. se un vincolo toglie credibilità al paese e blocca un nuovo parco. Gli Stati Generali. Recuperado de https://www.glistatigenerali.com/milano territorio-ambiente/piazzadarmi-se-un-vincolo-toglie-credibilita-al-paese-e-blocca-nuovo-parco/

Mas Hernández, R. (1999). La promoción inmobiliaria en los Ensanches del siglo XIX. Ciudad y Territorio. Estudios Territoriales, 31(119-120), 55-73.

Mas Hernández, R. (2003). La presencia militar en las ciudades. Orígenes y desarrollo del espacio urbano militar en España. Madrid, España: Catarata.

Masera, G. y Pavia, A. (1911). Pianta di Milano con l'indicazione del Piano Generale Regolatore Edilizio e di Ampliamento. Milán, Italia: Civiche Raccolte d'Arte Applicata ed Incisioni-Civica Raccolta delle Stampe Achille Bertarelli.

Melis, A. (1941). Le città militari. Urbanistica. Rivista dell'stituto Nazionale di Urbanistica, 10(2), 15-17.

Ministero della Difesa (2005). Decreto 28 febbraio 2005. Individuazione dei beni immobili in uso all'Amministrazione della difesa, non più utili ai fini istituzionali, da consegnare al Ministero dell'economia e delle finanze e per esso all'Agenzia del demanio. Recuperado de https://www.gazzettaufficiale.it/eli/id/2005/06/20/05A05915/sg

Ministero della Difesa (2010). Individuazione di alcuni immobili militari al fine del trasferimento al patrimonio disponibile dello Stato. Recuperado de https://www.gazzettaufficiale.it/atto/serie generale/caricaDettaglioAtto/originario?atto.dataPubblicaz ioneGazzetta=2010-06-29\&atto.codiceRedazionale=10A07841\&elenco30giorni=false

Montedoro, L. (Ed.). (2016). Open Mameli. Un percorso sperimentale di partecipazione. Santarcangelo di Romagna, Italia: Maggioli.

Morandi, C. (2005). Milano. La grande trasformazione urbana. Venecia, Italia: Marsilio.

Municipio 7 (2017a). Verbale n. 17 della seduta di municipio 730 gennaio 2017. Recuperado de http://mediagallery.comune.milano.it/cdm/objects/changeme:78041/datastreams/dataStream123102 46716294610/content

Municipio 7 (2017b). ATU 8 A - Ambiti di trasformazione urbana - Area Piazza d'Armi - Proposta del Consiglio di Municipio 7. Recuperado de http://lorenzoboati.it/wp-content/uploads/2017/05/DeliberaMunicipio-7-Piazza-dArmi-29-maggio-2017.pdf

Muñoz, F. (2008). Urbanalización. Paisajes comunes, lugares globales. Barcelona, España: Gustavo Gili.

ACE, 16 (4.6) CC BY-ND 3.0 ES | UPC Barcelona, España | Propiedades militares y nuevas áreas de centralidad. El 
Neri, R. (Ed.). (2014). Milano. Caserme e aree militari. Workshop Scuola di Architettura Civile. Santarcangelo di Romagna, Italia: Maggioli.

Oliva, F. (1993). Il riuso delle aree dismesse. En G. Campos Venuti y F. Oliva (Eds.), Cinquant'anni di urbanistica in Italia 1942-1992 (pp. 181-200). Bari-Roma, Italia: Laterza.

Oliva, F. (2002). L'urbanistica di Milano. Quel che resta dei piani urbanistici nella crescita e nella trasformazione della città. Con sei itinerari. Milán, Italia: Hoepli.

Pagano, G. (1941). Nuovi orizzonti di urbanistica militare. Casabella, 14(161), 20-31

Pugliese, R. (Ed.). (2016). Progetti per la Piazza d'Armi. Il sistema delle caserme milanesi. Architettura e riqualificazione urbana. Santarcangelo di Romagna, Italia: Maggioli.

Riboldazzi, R. (2008). Una città policentrica. Cesare Chiodi e l'urbanistica milanese nei primi anni del fascismo. Milán, Italia: Polipres.

Rigotti, G. (1938). Ruralizzare le caserme. Urbanistica, 73), 152-155.

Rosa, G. (1982). Il mito della capitale morale. Letteratura e pubblicistica a Milano fra Otto e Novecento. Milán, Italia: Edizioni di Comunità.

Sánchez Pingarrón, J. (2018). Orígenes y desarrollo de la politica de enajenación de infraestructuras militares en España. La reconversión de espacios militares para uso universitario. Madrid, España: Universidad Nacional de Educación a Distancia.

Santarossa, A. y Scirè Risichella, G. (Eds.). (2016). Un paese di Primule e caserme. Pordenone, Italia: Cinemazero.

Savorra, M. y Zucconi, G. (Eds.). (2009). Spazi e cultura militare nella città dell'Ottocento. Città e Storia, 4(2). Roma, Italia: Croma.

Scotti, A. (1989). Il Foto Bonaparte. Un'utopia giacobina a Milano. Milán, Italia: Franco Angeli.

Sklair, L. (2017). The Icon Project: Architecture, Cities and Capitalist Globalization. Nueva York, Estados Unidos: Oxford University Press.

Solà-Morales i Rubió, M. de, et al. (1974). Barcelona: remodelación capitalista o desarrollo urbano en el sector de La Ribera oriental. Barcelona, España: Gustavo Gili.

Storelli, F. y Turri, F. (Eds.). (2014). Le caserme e la città. I beni immobili della Difesa tra abbandoni, dismissioni e riusi. Roma, Italia: Palombi.

Tacchi, E. M. (2010). La distanza sociale. Milano e i ghetti virtuali. Milán, Italia: Franco Angeli.

Torricelli, A. y Rampi, M. T. (1989). Milano: Castello, quartiere delle milizie, città militare nella trasformazione del centro e nella costruzione della periferia. En Aa. Vv., Esercito e città. Dall'Unità agli anni Trenta. Atti del Convegno di studi (Perugia, 11-14 maggio 1988). Tomo // (pp. 871-877). Roma, Italia: Ministero per i beni culturali e ambientali, Ufficio centrale per i beni archivistici.

Tosi, A. (2017). Le case dei poveri. É ancora possibile pensare un welfare abitativo?. Sesto San Giovanni, Italia: Mimesis.

Uberti, G. (2015). Lo spazio urbano della Piazza d'Armi di Milano: relazione storica. Recuperado de https://sb839e10122a410ff.jimcontent.com/download/version/1479735743/module/13710695722/nam e/Relazione\%20storica\%20Piazza\%20Armi2 ultima completa.pdf

Ugolini, M. (2016). Intorno all'acqua. Un grande spazio aperto come costruttore di urbanità. En Pugliese, R. (comp.), Progetti per la Piazza d'Armi. Il sistema delle caserme milanesi. Architettura e riqualificazione urbana (pp. 135-160). Santarcangelo di Romagna, Italia: Maggioli.

Zucconi, G. (1989). La città contesa. Dagli ingegneri sanitari agli urbanisti (1885-1942). Milán, Italia: Jack Book.

ACE, 16 (46) CC BY-ND 3.0 ES | UPC Barcelona, España | Propiedades militares y nuevas áreas de centralidad. El caso de la Plaza de Armas de Milán. DOI: http://dx.doi.org/10.5821/ace.16.46.10366 